\title{
A Tale of Two Hierarchies: Interactive Effects of Power Differentiation and
}

\author{
Status Differentiation on Team Performance
}

\author{
Nicholas A. Hays \\ Michigan State University \\ Xue Yang \\ Nanjing University \\ Andrew Yu \\ University of Melbourne \\ John R. Hollenbeck \\ Michigan State University
}

\author{
Jessica Li \\ Georgia Tech University \\ Kyoungjo Oh \\ University of Connecticut \\ Ya-Ru Chen \\ Cornell University \\ Bradley Jamieson \\ Michigan State University
}

\begin{abstract}
Scholars have long wrestled with whether hierarchical differentiation is functional or dysfunctional for teams. Building on emerging research that emphasizes the distinction between power (i.e., control over resources) and status (i.e., respect from others), we aim to help reconcile the functional and dysfunctional accounts of hierarchy by examining the effects of power differentiation on team performance, contingent on status differentiation. We theorize that power differentiation is dysfunctional for teams with high status differentiation by increasing knowledge hiding, which undermines team performance. In contrast, we predict that power differentiation is functional for teams with low status differentiation by decreasing knowledge hiding, which improves team performance. In a field study, we found that power differentiation harmed team performance via knowledge hiding in teams with high status differentiation, but power differentiation had no effect on knowledge hiding or performance in teams with low status differentiation. In an experiment, we again found that power differentiation harmed team performance by increasing knowledge hiding in teams with high status differentiation. However, power differentiation improved team performance by decreasing knowledge hiding in teams with status equality. Finally, in a third study, we confirm the role of status differentiation in making team climates more competitive and examine the effect of power-status alignment within teams, finding that misalignment exacerbates the dysfunctional effects of power differentiation in teams with high status differentiation. By examining how power and status hierarchies operate in tandem, this work underscores the need to take a more nuanced approach to studying hierarchy in teams.
\end{abstract}

Keywords: power, status, hierarchical differentiation, team performance, knowledge hiding, work teams

Published in Organization Science

Citation: Hays, N.A., Li, J., Yang, X., Oh, J.K., Yu, A., Chen, Y.-R., Hollenbeck, J.R., \& Jamieson, B. (2021). A tale of two hierarchies: Interactive effects of power differentiation and status differentiation on team performance. Organization Science. https://doi.org/10.1287/orsc.2021.1540

Note: This paper is not the copy of record and may not exactly replicate the final, authoritative version of this article. The final article is available online at https://doi.org/10.1287/orsc.2021.1540 


\section{Introduction}

Hierarchy, defined as differentiation along a socially valued dimension (Magee and Galinsky 2008), is ubiquitous in organizations (Ilgen et al. 2005; Kozlowski and Bell 2013). Unsurprisingly, therefore, hierarchy has generated significant interest among organizational scholars at all levels of analysis, including micro-level research on individuals (e.g., DeCelles et al. 2012; Pitesa and Thau 2013; Tost et al. 2013), meso-level research on teams (e.g., Bunderson and Reagans 2011; Greer and van Kleef 2010; Hollenbeck et al. 2012), and macro-level research on organizations and markets (e.g., Jensen and Kim 2015; Podolny 1993; Williamson 1981).

Despite significant scholarly attention to hierarchy, one basic question that remains unanswered is whether hierarchy is functional or dysfunctional for teams. The functional account of hierarchy posits that hierarchy boosts team effectiveness by facilitating coordination of action and decision-making (Anderson and Brown 2010). In contrast, the dysfunctional account of hierarchy posits that hierarchy undermines team effectiveness by engendering conflict and competition between team members (Greer et al. 2018). Empirical evidence supports both the functional and dysfunctional accounts (e.g., Bendersky and Hays 2012; Carzo and Yanouzas 1969; Halevy et al. 2011b; Van Bunderen et al. 2018). Organizations have been similarly conflicted, with some organizations eschewing hierarchy (e.g., IDEO; Amabile et al. 2014), and others struggling with a lack of hierarchy (e.g., Zappos; Lam 2016). Thus, the debate about the functionality of hierarchy rages on.

We posit that disentangling hierarchical differentiation based on power, defined as asymmetric control over valued resources, and status, defined as the extent to which an individual is respected by others (Magee and Galinsky 2008), can reconcile the functional and dysfunctional accounts of hierarchy. At the individual level, power and status have divergent and interactive psychological effects (Anicich et al. 2016; Blader and Chen 2012; Blader et al. 2016; Fast et al. 2012). At the team level, we theorize that power differentiation and status differentiation interactively impact team effectiveness. We define power differentiation as the relative concentration of power among members of a team and, similarly, status differentiation as the relative concentration of status among members of a team (Harrison and Klein 2007). Specifically, we predict that, contingent on the level of status differentiation, power differentiation can increase or decrease knowledge hiding, which subsequently undermines or benefits team performance. Knowledge hiding is defined as "an intentional attempt by an individual to withhold or conceal knowledge" (Connelly et al. 2012, p. 65). Thus, we posit that status differentiation serves as a "switch" that makes power differentiation either functional or dysfunctional for teams.

We test our predictions in two studies that span methodology (lab experiment and field survey), sample (undergraduates and working teams), and cultural context (American and Chinese). In a third study, we confirm the role of status differentiation in making team climates more competitive, which is at the heart of our arguments about the moderating role of status differentiation. We also examine the effect of within-team alignment of power and status, predicting and finding that misalignment of power and status exacerbates the dysfunctional effects of power differentiation combined with status differentiation.

Our research makes several contributions to the literatures on teams and hierarchy. First, we help reconcile the functional and dysfunctional accounts of hierarchy by showing that power differentiation and status differentiation interactively affect team effectiveness. This sheds light on a topic that has been a longstanding debate among hierarchy scholars (e.g., Greer et al. 2018). Second, although previous research has illuminated distinct effects of power and status for individuals (Anicich et al. 2016; Blader and Chen 2012; Blader et al. 2016; Fast et al. 2012), we answer calls to consider the team-level effects of differentiation based on power or status. Notably, individual-level effects do not translate neatly to the team level because teams involve interactions between people with differing levels of power and status (Greer et al. 2017). Third, this paper is the first to disentangle power differentiation and status differentiation and then examine how they operate in tandem, as they typically do in organizations. Although past research has examined effects of hierarchical differentiation, this work has tended to 
examine differentiation based on either power or status in isolation (Greer and van Kleef 2010; Halevy et al. 2011b; Ronay et al. 2012). Finally, this research examines how the level of alignment between power and status hierarchies within teams affects team processes. For individuals, misalignment between one's power and status can have toxic interpersonal consequences (Anicich et al. 2016; Fast et al. 2012). We examine the consequences of misalignment for teams.

\section{Hierarchy and Team Effectiveness: Functional and Dysfunctional Accounts}

Two distinct accounts of hierarchy exist in the literature. The functional account of hierarchy argues that hierarchical differentiation improves team effectiveness by coordinating action and collective decision making (Anderson and Brown 2010; March and Simon 1958; Van Vugt et al. 2008). Hierarchies coordinate action by establishing complementary roles, norms, and expectations (Anicich et al. 2015; Dornbusch and Scott 1975; Halevy et al. 2011b; Tiedens and Fragale 2003). Hierarchies coordinate collective decision making by providing one or a few group members with disproportionate control and influence over the group, which can improve decision-making efficiency (Keum and See 2017; Ridgeway and Diekema 1989; Van Vugt 2006). As a result, the team members with the greatest control and influence can facilitate discussions, coordinate the exchange of information and use of resources, make decisions quickly, and take action.

The dysfunctional account of hierarchy argues that hierarchical differentiation interferes with performance by engendering counterproductive conflict and competition among group members (Bendersky and Hays 2012; Greer et al. 2018; Greer and van Kleef 2010). Hierarchy can stifle effective idea generation and information exchange within teams, and ultimately undermine team effectiveness (Becker and Baloff 1969; Keum and See 2017; Ridgeway and Diekema 1989; Tost et al. 2013; Van der Vegt et al. 2010; Van Vugt 2006; Woolley et al. 2010). High-rank individuals often have a sense of deservingness and entitlement, leading them to hoard resources for themselves, and ignore and denigrate lower-rank team members (De Cremer and Van Dijk 2005; Georgesen and Harris 2000; Hays and Blader 2017; Kipnis 1972; Pettit and Sivanathan 2012; Tost et al. 2012). At the same time, low-rank individuals may withhold their perspectives out of a concern that their contributions will be discounted or ignored (Bunderson and Reagans 2011; Torrance 1955). Thus, hierarchy can hinder the exchange of information among team members.

We argue that considering the specific basis of the hierarchical differentiation is an important means of reconciling the functional and dysfunctional accounts of hierarchy for organizations. Status and power are two of the most prevalent and fundamental bases of social hierarchy (Blader and Chen 2014; Blau 1964; Fiske 2010; Kemper and Collins 1990; Magee and Galinsky 2008). Earlier definitions obscured the distinctions between power and status by conflating them with related constructs (e.g., prominence) and shared consequences (e.g., influence) (Magee and Galinsky 2008). For example, French and Raven (1959) defined power as "potential influence of some individual or group over an [other] individual" (p. 400), and Anderson and colleagues (2001) defined status as respect, prominence, and influence. Fortunately, social hierarchy researchers have recognized the importance of differentiating between bases of hierarchy (power and status) and distinguishing these bases from related constructs and consequences. This is accomplished with the definitions we adopt here, which highlight the distinctiveness of power and status.

\section{Disentangling Power and Status for Individuals}

Although power and status are both sources of influence over others (Magee and Galinsky 2008), they differ in important ways, most significantly in their loci and reliance on social conferral processes. Power is a function of the level of valued resources one controls and is therefore largely located in the individual. Although power requires that others ascribe value to the resource one controls (Emerson 1962), resources often have inherent value (e.g., money) or fulfill core psychological needs (e.g., group membership) and therefore individuals often cannot simply decide to devalue the resource. In contrast, 
status is the amount of respect, prestige, and esteem that one has in the eyes of others and is therefore located in observers (Berger et al. 1972). Status is wholly reliant on voluntary social conferral processes; individuals have status to the extent that others are willing to confer it, and they gain or lose status to the extent others decide that individuals deserve more or less respect. Moreover, status is continuously negotiated through interactions with others, as individuals attempt to demonstrate their competence and group orientation (Bendersky and Hays 2012; Strauss et al. 1963). As Magee and Galinsky (2008) describe, "power, more than status, therefore, is a property of the actor. Status, more than power, is a property of co-actors and observers" (p. 364).

Empirical research that disentangles power and status has uncovered distinct consequences of these bases of hierarchy for individuals. For example, because status is more reliant than is power on voluntary, continuous social conferral processes, high status (vs. low status) tends to orient people outwardly to their relationships, manifest as increased perspective-taking and justice enactment toward others (Blader and Chen 2012; Blader et al. 2016). In contrast, high power (vs. low power) tends to orient people inwardly, decreasing perspective-taking and justice enactment toward others (Blader et al. 2016; Galinsky et al. 2006). Moreover, power and status can have interactive consequences for individuals. In particular, individuals with high power but low status tend to disparage and initiate conflict with others (Anicich et al. 2016; Fast et al. 2012). In sum, prior theoretical and empirical work highlights the distinctiveness of power and status as bases of hierarchy.

\section{Disentangling Power Differentiation and Status Differentiation for Teams}

Building on past research that disentangles effects of individuals' power and status, we disentangle teams' power differentiation and status differentiation. Whereas power and status reflect an individual's position in a hierarchy, power differentiation and status differentiation reflect a team's distribution of these bases of hierarchy. Moreover, we conceptualize differentiation in power or status in vertical terms (i.e., disparity; Harrison and Klein 2007) because power and status have value for individuals (Anderson et al. 2015; Deci and Ryan 1987). Central to vertical differentiation is the notion of asymmetry, which reflects the idea that differentiation is greatest when a few are advantaged relative to many. A high level of differentiation means that power or status in a team is concentrated in one or two team members, whereas a low level of differentiation means that power or status are relatively evenly distributed among members of the team.

A high degree of power differentiation means that a small number of powerful team members can coordinate the actions of the team by integrating information, allocating resources, and making decisions, whereas the less powerful members must carry out those decisions. These differences in decision-making authority and resource control underlie the functional account of hierarchy (Anderson and Brown 2010; Dornbusch and Scott 1975). However, power differentiation can also lead to competition and conflict (Greer et al. 2017; Van Bunderen et al. 2018). These dynamics underlie the dysfunctional account of hierarchy. Thus, paralleling the functional and dysfunctional accounts of hierarchy, we theorize that power differentiation can be either functional or dysfunctional. We posit that status differentiation - by shaping teams' climate and goals, from competitive and self-oriented to cooperative and team-oriented (Hays and Bendersky 2015) - serves as a "switch" that determines whether power differentiation is functional or dysfunctional.

\section{Dysfunctional Hierarchies: Power Differentiation Combined with High Status Differentiation}

Because status is continuously negotiated among team members, hierarchies based on status differentiation are perceived as relatively mutable, which creates opportunities for team members to jockey for position (DeRue and Ashford 2010; Hays and Bendersky 2015; Strauss et al. 1963; Sutton and Hargadon 1996). The perceived mutability of status differentiation tends to heighten competition between team members, causing them to prioritize oneself over the team (Case et al. 2018; Maner and Mead 2010; Wright 1997; Wright et al. 1990). For example, Hays and Bendersky (2015) found that status 
differentiation made participants more likely to keep resources for themselves rather than contribute them to the group, compared to participants in a control condition in which status differentiation was not salient. Thus, teams with a high level of status differentiation are likely characterized by a competitive team climate, which shapes team members' interactions (Schneider et al. 2013; Zohar and Hofmann 2012).

In teams with a high level of status differentiation, we posit that power differentiation will be dysfunctional by increasing members' tendency to withhold an important resource - knowledge - rather than sharing it with the team. That is, in these teams, we expect that increasing levels of power differentiation will heighten knowledge hiding. Importantly, knowledge hiding is distinct from simply failing to share knowledge. Whereas failing to share knowledge can result from the absence of knowledge, knowledge hiding is deliberate, and is often self-interested and strategic (Connelly et al. 2012). Because a high level of status differentiation creates a climate characterized by competition and self-focus, we predict that power differentiation will increase knowledge hiding by eliciting dysfunctional, complementary psychological effects of high and low power (Tiedens and Fragale 2003; Tiedens et al. 2007). High power heightens focus on one's goals (Guinote 2007; Keltner et al. 2003), which tend to be competitive and self-interested in teams with a high level of status differentiation (Hays and Bendersky 2015). As a result, high-power team members are more likely to allocate resources in selfinterested ways, such as by hiding information (among other resources) from others (Kipnis 1972; Magee and Langner 2008; McClelland 1970). Moreover, high-power team members may distrust others' intentions (Inesi et al. 2012), which can heighten knowledge hiding (Connelly et al. 2012).

At the same time, less powerful team members may engage in knowledge hiding out of a concern that information, if shared, will be ignored, discounted, or punished by high-power members (Humphrey 1985; Postmes et al. 2001; Sande et al. 1986; See et al. 2011; Wittenbaum et al. 2004). Perceptions of others' hostility can lead to greater knowledge hiding (Connelly et al. 2012). Although the psychological reasons for knowledge hiding may differ somewhat as a function of team members' position in the power hierarchy, the behavioral consequence is the same: a high degree of power differentiation predicts elevated levels of knowledge hiding. In contrast, when power differentiation is minimized, power will be less salient (Greer et al. 2017) and the dysfunctional, complementary psychological effects of high and low power described above will be attenuated. Thus, we expect that, in teams with a high degree of status differentiation, increasing levels of power differentiation will unleash the dysfunctional effects of hierarchy by encouraging knowledge hiding.

\section{Functional Hierarchies: Power Differentiation Combined with Low Status Differentiation}

When status differentiation is minimized, all team members are respected relatively equally, regardless of their formal roles or authority. Minimizing status differentiation makes status less salient overall, with team members less focused on or concerned about their own or others' status (Greer et al. 2017). As a result, teams with low status differentiation are characterized by less competitive team climates and team members are less focused on their own self-interests (Hays and Bendersky 2015). Instead, team members tend to be more cooperative, prioritizing collective interests over individual interests (Cunningham et al. in press; Tyler and Blader 2003). Moreover, status equality reduces the tendency to evaluate team members' ideas through the lens of their relative status, a lens that tends to amplify the perceived value of ideas from high-status members and diminish the perceived value of ideas from low-status members (Berger et al. 1972).

In teams with a low level of status differentiation, we posit that power differentiation will be functional by decreasing knowledge hiding. Because a low level of status differentiation creates a climate characterized by cooperation and prioritization of the group interests, we predict that power differentiation will elicit functional, complementary psychological effects of high and low power (Tiedens and Fragale 2003; Tiedens et al. 2007). Specifically, the cooperative climate created by status equality is likely to encourage more powerful team members to pursue group goals by using their power 
in prosocial ways that benefit the group (Chen et al. 2001; Magee and Langner 2008; McClelland 1970). Pursuing group goals means that high-power team members are less likely to withhold and hide knowledge for themselves or discount others' views and contributions (Tost et al. 2012). Instead, highpower team members can facilitate balanced discussions, identify gaps where they exist, and elicit information as needed (Bunderson and Reagans 2011).

Low-power team members are less likely to engage in knowledge hiding when high-power members elicit their participation and cooperation (De Cremer and van Knippenberg 2002; Tyler 2002). Moreover, low-power team members are less likely to withhold their perspectives if they trust others, knowing that their contributions will be considered rather than ignored (Connelly et al. 2012; Tost et al. 2013). Once again, the psychological reasons for knowledge hiding may differ somewhat by level of power, but the behavioral consequence is the same: a high degree of power differentiation decreases knowledge hiding. As before, when power differences between team members are absent or minimized, power will be less salient (Greer et al. 2017) and the functional, complementary psychological effects of high and low power described above will be attenuated. Thus, we predict that, in teams with a low level of status differentiation, increasing levels of power differentiation will unleash the functional effects of hierarchy by discouraging knowledge hiding.

In sum, we argue that power differentiation can be either functional or dysfunctional, contingent on the level of status differentiation present in a team. Because a high level of status differentiation encourages competition and focuses team members on their self-interests, we predict that increasing levels of power differentiation in such teams will have the dysfunctional effect of heightening knowledge hiding among team members. Conversely, because status equality encourages cooperation and focuses team members on the interests of the group, we predict that increasing levels of power differentiation in such teams will have the functional effect of decreasing knowledge hiding among team members. More formally, we predict:

Hypothesis 1: Status differentiation moderates the effect of power differentiation on knowledge hiding, such that (a) the effect of power differentiation will be positive when status differentiation is high, and $(b)$ the effect of power differentiation will be negative when status differentiation is low.

Considering that a core function of teams is to bring greater information to bear on tasks than could an individual (Kozlowski and Bell 2013), knowledge hiding tends to undermine team effectiveness (Cerne et al. 2014; Connelly et al. 2012; Haas and Park 2010). Instead, open communication is critical for team effectiveness (Dionne et al. 2004; Gardner et al. 2012; Guzzo and Dickson 1996). This is particularly true in decision-making groups with a high degree of interdependence (Evans et al. 2015; Lam and Schaubroeck 2000). In light of our predictions about the interactive effects of power differentiation and status differentiation on knowledge hiding, this implies that when status differentiation is high, power differentiation will increase knowledge hiding and hinder team performance, whereas when status differentiation is low, power differentiation will decrease knowledge hiding and improve team performance. Thus, we predict:

Hypothesis 2: Status differentiation moderates the indirect effect of power differentiation on team performance via knowledge hiding, such that (a) the indirect effect of power differentiation will be negative when status differentiation is high, and $(b)$ the indirect effect of power differentiation will be positive when status differentiation is low.

Figure 1 depicts our theoretical model.

Insert Figure 1 about here 


\section{Overview of Studies}

We test Hypotheses 1 and 2 in two studies that span sample, methodology, and culture. We conducted Study 1 in a field setting with long-term project teams in Chinese organizations. This study allows us to test our hypotheses in a natural setting to demonstrate external validity. Study 2 is a laboratory experiment conducted with undergraduate participants in the U.S. In the study, we manipulate power differentiation and status differentiation to examine the proposed causal claims. Moreover, Study 2 allowed us to test an intervention intended to minimize status differentiation. Study 3 is an online experiment that allows us to confirm the role of status differentiation in making team climates competitive (versus cooperative), which is central in our theoretical arguments and predictions. Moreover, we explore the role of within-team alignment between members' power and status. We elaborate on the topic of alignment before Study 3.

\section{Study 1: \\ Examining Power Differentiation and Status Differentiation in a Field Setting}

\section{Methods}

\section{Participants and Procedure}

We employed a professional data collection company to recruit long-term project teams in China to participate in our research. The company provided data from teams in which all team members responded to the surveys. In the end, 256 full-time employees (178 males, $69.5 \%$ ) organized into 50 work teams participated in this study. Teams ranged in size from two to eight employees $(M=5.16, S D=1.48)$ and came from companies in the computer, hospitality, and logistics industries. Teams were created by the members themselves to work on self-initiated projects. Each team was responsible for developing a prototype of an information technology product or service, and projects lasted 3-12 months. As examples, one team was developing a mobile application to pay for public parking and another was developing food delivery software.

We collected data for this study as part of a larger data collection effort. Each participant was compensated about $\$ 15$ (100 RMB) for completing each survey. We collected three waves of survey data at the beginning (Time 1), mid-point (Time 2), and end (Time 3) of each project. At Time 1, each participant provided round-robin ratings of each other team member's power and status. Because of our round-robin measures and space constraints in the surveys, we used one to two items to measure each construct. Power was measured using two items $(r=.74, p<.001$; "Member $\mathrm{X}$ has decision making power over our product development in our team," and "Member X has decision making power over project management in our team"), based on the definition of power in Magee and Galinsky (2008). Status was measured by one item ("I respect Member X and view him/her as having high status"), adapted from Anderson et al. (2006). All responses were on a seven-point scale from 1 (strongly disagree) to 7 (strongly agree).

We calculated each participant's power and status by averaging the ratings of them provided by their team members. We then calculated power differentiation and status differentiation values for each team as the coefficient of variation $(\mathrm{CV})$, a standard measure of differentiation on a valued attribute (i.e., power or status) (Harrison and Klein 2007). CV is equal to the within-team standard deviation divided by the within-team mean. Thus, power differentiation is the CV of the participants' power scores within each team and status differentiation is the CV of the participants' status scores within each team.

At Time 2, each participant provided round-robin ratings of knowledge hiding in their interactions with each other team member. Participants responded to the item, "Regarding this work project, I exchange a wide range of information with Member X" (reverse-coded), adapted from MesmerMagnus and DeChurch (2009). We calculated a team-level knowledge hiding score by averaging the values of all members. Because participants were rating their own behavior and not a group process, this 
represents an additive construct for which consensus is not expected or required to justify aggregation to the team level (Chan 1998).

At Time 3, the leader of each team assessed team performance. Although there were no formal team leaders appointed by the organizations at the beginning of these projects, leaders naturally emerged. Prior to the Time 3 survey, researchers asked members of each team to nominate a team leader, and the most frequently nominated team members were selected to rate the team's performance in the Time 3 survey. Team leaders responded to a nine-item measure $(\alpha=.84)$ of team performance used in previous research on product development teams (Tiwana and Keil 2007). Leaders rated teams' performance relative to other teams on nine dimensions (e.g., work quality) on a seven-point scale from 1 (much worse) to 7 (much better). ${ }^{1}$

Given evidence of gender differences in motivation to acquire power and status (Hays 2013), we control for team gender composition in our hypothesis tests. Moreover, we also calculated and control for the team-mean level of power and the team-mean level of status among individuals because mean levels should be controlled for when testing the effect of differentiation (Roberson et al. 2007). Finally, we control for the within-team standard deviation of knowledge hiding when predicting team-mean knowledge hiding to ensure that our effects were driven by power differentiation and status differentiation (and their interaction), above and beyond any effects of differentiation on knowledge hiding itself. ${ }^{2}$

Insert Table 1 about here

\section{Results}

Table 1a includes descriptive statistics and correlations between variables. We tested our hypotheses using SEM path analysis, with bootstrapped standard errors (with 1,000 replications). We standardized power differentiation and status differentiation prior to analysis and report bias-corrected confidence intervals.

\section{Interactive Effects of Power and Status Differentiation on Knowledge Hiding}

Consistent with Hypothesis 1, the interaction between power differentiation and status differentiation (at Time 1) on knowledge hiding (at Time 2) was significant, $B=.19,95 \%$ CI: [.034, .391]. ${ }^{3}$ As predicted in Hypothesis 1a, power differentiation was significantly and positively related to knowledge hiding in teams with high status differentiation (+1 SD), $B=.34,95 \%$ CI: $[.102, .563]$ (see Figure 2). However, in teams with low status differentiation (-1 SD), power differentiation was not significantly related to knowledge hiding, $B=-.05,95 \%$ CI: $[-.339, .225]$. Thus, Hypothesis $1 \mathrm{~b}$ was not supported. ${ }^{4}$

\section{Conditional Indirect Effects of Power Differentiation on Team Performance via Knowledge Hiding}

As expected, knowledge hiding (at Time 2) was negatively associated with team performance (at Time 3), $B=-.40,95 \%$ CI: [-.726, -.014]. Consistent with Hypothesis 2, status differentiation moderated the indirect effect of power differentiation on team performance via knowledge hiding, $B=-.08,95 \% \mathrm{CI}$ :

\footnotetext{
${ }^{1}$ A complete list of items for all measures across all studies is available in the Supplemental Materials.

${ }^{2}$ In addition to the control variables reported in the focal analysis, we conducted additional analysis in which we controlled for team size, project length (in months), and team functional area (i.e., research and development, marketing, and operations). The pattern of results remained the same with these additional control variables.

${ }^{3}$ Complete results, including control variables, for all studies are provided in the Supplemental Materials.

${ }^{4}$ We tested but found no evidence for differences in knowledge hiding as a function of individuals' power and status. Please see Supplemental Materials for details of this analysis.
} 
[-.209, -.004]. As predicted in Hypothesis 2a, when status differentiation was high (+1 SD), the indirect effect of power differentiation on team performance, via knowledge hiding, was significant and negative, $B=-.14,95 \%$ CI: [-.321, -.007]. However, in teams with low status differentiation (-1 SD), the indirect effect of power differentiation on team performance was not significant, $B=.02,95 \%$ CI: [-.080, .187]. Thus, Hypothesis $2 \mathrm{~b}$ was not supported.

Insert Figure 2 about here

\section{Discussion}

In this study, we found that power differentiation and status differentiation interactively affected knowledge hiding and, subsequently, team performance. In teams with a high level of status differentiation, power differentiation increased knowledge hiding and harmed team performance, as we predicted. However, in teams with a low level of status differentiation, power differentiation was unrelated to knowledge hiding or team performance. Thus, this study provides partial support for our theorizing. Specifically, we found evidence of the dysfunctional effects of power differentiation but not the functional effects.

One reason why this study may not have supported our theorizing about potential functional effects of power differentiation is because power differentiation and status differentiation were positively correlated $(r=.41, p=.004)$, whereas our theorizing treats them as independent constructs. The positive correlation suggests that there may be relatively few teams with a high level of power differentiation and a low level of status differentiation, which is precisely where we expect teams to be most effective. That is, if power differentiation tends to be positively correlated with status differentiation across teams, we are more likely to find the dysfunctional effects we predicted (when a high level of power differentiation is combined with a high level of status differentiation) than to find the functional effects we predicted (when a high level of power differentiation is combined with a low level of status differentiation).

The results of Study 1 suggest that, in the presence of a high level of power differentiation, teams may naturally drift toward a high level of status differentiation, despite the detrimental effects of this combination. Thus, in teams with a high level of power differentiation, proactive interventions may be necessary to encourage status equality (or at least minimize status differentiation), to produce the most effective teams that we stipulated. Taking the view that experiments have value not only in demonstrating what does happen but also what can happen (Berkowitz and Donnerstein 1982; Colquitt 2008; Ilgen 1985), we designed Study 2 to test an intervention intended to encourage status equality. We expect this intervention to produce the proposed functional effect of power differentiation in the presence of low status differentiation.

\section{Study 2: Examining Causality and Testing Status Equality Intervention}

In this study, we manipulated our independent variables to examine the interactive effects of power differentiation and status differentiation on knowledge hiding and team performance. This experiment allows us to test an intervention intended to minimize status differentiation, particularly in the presence of a high degree of power differentiation. In addition, we employed a validated measure of knowledge hiding (adapted from Connelly et al. 2012) as a better test of our theorized mechanism than was possible in Study 1. Finally, we used a measure of objective performance rather than having team leaders rate the performance of their own teams. We utilized an engaging, interdependent team task that requires pooling of information to converge on accurate decisions, which closely resembles what organizational teams typically do. 


\section{Method}

\section{Participants and Procedure}

Three hundred fifteen undergraduate students (174 males, 55.2\%) at a large U.S. university, organized into 63 five-person teams, participated in our study in exchange for course credit. Participants averaged 21.31 years in age ( $\mathrm{SD}=2.26$ years), and 70.3 percent reported English as their first language.

Teams were randomly assigned to one of four conditions in a 2 (power differentiation: high vs. low) $\times 2$ (status differentiation: high vs. low) study design. Each session consisted of 15 participants organized into three teams. As an additional performance incentive, the highest scoring team in each study session (i.e., one of the three teams per session) received a \$50 cash reward, divided equally among the team members.

We used a strategic decision-making simulation, LDX, that has been used in prior research as the platform for this study (see Lee et al. 2015; Lorinkova et al. 2013; Sleesman et al. 2018). In the simulation, team members must work together to allocate scarce team resources used to seek out targets while simultaneously protecting their own resources from threats in an initially unknown and dynamic environment. Individual team members have unique roles that provide them control over specific resources and decisions, and team success is dependent on effective communication, coordination, and team decision-making. Knowledge hiding could result in inefficient use of team assets and ineffective decision-making.

Upon arrival, we randomly assigned participants to a five-person team and moved each team into a private room for the study. At the beginning of each session, participants individually completed a presurvey, which included demographic questions, their college GPA, college admission test scores, and work experience (ostensibly used to assign roles in some conditions, as described below). Next, participants watched a brief video to familiarize themselves with the simulation. Following the video, we assigned participants to their roles within the team. The role assignments varied as a function of experimental condition in the 2 (power differentiation) $\times 2$ (status differentiation) design, as we describe below.

High Power Differentiation. In the high power differentiation conditions, we assigned each team member to one of five roles: Mission Commander, Director of Operations, Director of Intelligence, Operations Analyst, or Intelligence Analyst. The Mission Commander had the highest level of power within the team, the two directors had a moderate level of power, and the two analysts had the lowest level of power. We did not differentiate the power levels between the two director roles or between the two analyst roles. During the simulation, analysts made the first series of decisions during the analyst planning phase. In the subsequent director planning phase, directors could approve or revise any decisions made by the analyst within their division (e.g., Director of Operations could approve or revise decisions made by the Operations Analyst). In the final, commander planning phase, the Mission Commander could approve or revise any decisions made by other members of the team. Thus, directors had authority over the analysts' deployment decisions and resources, and the Mission Commander had authority over all team decisions and resources. In addition, the Mission Commander maintained the common operational picture, a record of information about enemy targets and an important component of determining the team's strategy. We reinforced these power differences with an organizational chart displaying a threelevel hierarchy. The experimenter wrote participants' names on the organization chart as role assignments were announced.

Low Power Differentiation. In the low power differentiation conditions, we assigned each team member to one of the following roles: Liaison Officer, Signal Intelligence Officer, Human Intelligence Officer, Offensive Operations Officer, and Support Operations Officer. We told participants that power was equally distributed across all members of the team and no member was more powerful than any other. During the simulation, the two Intelligence and two Operations Officers all made decisions 
simultaneously and were responsible for their own unique resources, while the Liaison Officer's role was to help facilitate the decision-making process among the team members and to maintain the common operational picture. No member of the team had authority to approve or revise other members' decisions. Power equality was reinforced with an organizational chart displaying all participants at an equal hierarchical level. The experimenter wrote participants' names on the organization chart as role assignments were announced.

High Status Differentiation. In the high status differentiation conditions, we informed participants that some roles were more important than other roles to team success, and therefore the team members holding the most important roles should be more respected than the other members. Moreover, we informed participants that roles would be assigned based on each person's relative leadership potential, determined from their responses in the pre-survey. In reality, roles were randomly assigned. We also accentuated status distinctions between roles using various props to signal status differences. Specifically, the organizational chart depicted the high-status Mission Commander (in the high power differentiation condition) or Liaison Officer (in the low power differentiation condition) title in a larger, more prominent font, accentuated by gold stars. Participants in these roles were also provided with fancy pens and notepads (Dubois et al. 2012; Rucker and Galinsky 2008). The low-status analysts' (in the high power differentiation condition) or operations officers' (in the low power differentiation condition) titles were depicted in smaller font with no accentuating stars, and participants received inexpensive pens and notepads.

Low Status Differentiation. In the low status differentiation conditions, we stated that all team members should be respected equally because all roles were equally important. We did not mention a leadership aptitude score and all participants received the same pens and notepads.

In summary, in the high power differentiation-high status differentiation condition, we informed participants that the Mission Commander was the most powerful and respected role on the team, the Directors were the second most powerful and respected roles, and the Analysts were the least powerful and least respected roles. In the high power differentiation-low status differentiation condition, we informed participants that while the Mission Commander was the most powerful role on the team, the Directors were the second most powerful roles, and the Analysts were the least powerful roles, all team members should respect each other equally. In the low power differentiation-high status differentiation condition, we informed participants that all roles had an equal amount of power and authority, however, the Liaison Officer was the most respected role on the team, the intelligence officers were the second most respected roles, and the operations officers were the least respected roles. In the low power differentiation-low status differentiation condition, we informed participants that all roles had an equal amount of power and authority, and all team members should respect each other equally.

Following the experimental manipulation, we conducted hands-on training to allow participants to practice their specific roles in the context of the simulation. After the training, each team proceeded through 10 rounds of the simulation. In the simulation, teams earned points by destroying enemy targets, and lost points each time the enemy destroyed the team's aircraft or attacked the team's base. We operationalize team performance using the teams' total score after playing ten rounds of the simulation.

After the simulation, participants responded to a four-item measure of knowledge hiding ( $\alpha=$ .87), adapted from Connelly et al. (2012), on a five-point scale from 1 (strongly disagree) to 5 (strongly agree). A sample item is: "I offered team members some other information instead of what they really wanted." As in Study 1, we calculated a team-level knowledge hiding score by averaging the values of the five members of each team. Again, because participants were rating their own behavior and not a group process, this represents an additive construct for which consensus is not required to justify aggregation to the team level (Chan 1998).

As a manipulation check, participants responded to a single, round-robin item about the extent to which each group member had high power, described as control over valuable resources, authority to 
make decisions, and responsibility for evaluating others. Similarly, participants responded to a single, round-robin item about the extent to which each group member had high status, described as being respected by others and sought out for advice. Responses to both round-robin items were on five-point scales from 1 (Never) to 5 (All of the time). Mirroring Study 1, we calculated a power score and a status score for each participant by averaging the power and status ratings, respectively, that $\mathrm{s} / \mathrm{he}$ received from other team members. We then calculated power differentiation within each team as the CV of team members' power, and status differentiation within each team as the CV of team members' status.

Consistent with Study 1, we controlled for the gender composition of teams (i.e., percentage of female team members). Moreover, because of the highly interactive nature of the simulation, our hypotheses related to knowledge hiding, and the influence of language proficiency on speaking up (Li et al. 2018), we also control for the percentage of team members whose native language was English. Finally, we controlled for the within-team standard deviation of knowledge hiding when predicting teammean knowledge hiding.

\section{Results}

Table $1 \mathrm{~b}$ includes descriptive statistics and correlations between variables. We tested our hypotheses using SEM path analysis, with bootstrapped standard errors (with 1,000 replications). We report bias-corrected confidence intervals.

\section{Manipulation Checks}

We first confirmed the effectiveness of our power differentiation and status differentiation manipulations. A 2 (power differentiation) $\times 2$ (status differentiation) ANOVA on power differentiation scores indicated a main effect of power differentiation, $F(1,59)=20.10, p<.001$. As intended, teams in the high power differentiation condition $(M=.22, S D=.11)$ had higher levels of power differentiation than did teams in the low power differentiation condition $(M=.12, S D=.06)$. Neither the main effect of status differentiation, $F(1,59)=1.60, p=.211$, nor the interaction of power differentiation and status differentiation, $F(1,59)=1.52, p=.223$, was significant.

A 2 (power differentiation) $\times 2$ (status differentiation) ANOVA on status differentiation scores indicated a main effect of status differentiation, $F(1,59)=11.33, p=.001$. As intended, teams in the high status differentiation condition $(M=.17, S D=.10)$ had higher levels of status differentiation than did teams in the low status differentiation condition $(M=.10, S D=.06)$. Unexpectedly, there was a main effect of power differentiation, $F(1,59)=5.03, p=.029$. Teams in the high power differentiation condition $(M=.15, S D=.10)$ had higher levels of status differentiation than did teams in the low power differentiation condition $(M=.11, S D=.07)$. This indicates that the presence of power differentiation within the team had the unanticipated side effect of heightening status differentiation as well. ${ }^{5}$ The interaction between power differentiation and status differentiation was not significant, $F(1,59)=.27, p$ $=.604$.

\section{Interactive Effects of Power and Status Differentiation on Knowledge Hiding}

As expected, we found a significant interaction of power differentiation and status differentiation on knowledge hiding, $B=.48,95 \%$ CI: [.191, .788]. Supporting Hypothesis 1a, power differentiation has a positive effect on knowledge hiding in the high status differentiation condition, $B=.30,95 \% \mathrm{CI}$ : [.060, .537] (see Figure 3). Supporting Hypothesis $1 \mathrm{~b}$, power differentiation has a negative effect on knowledge hiding in the low status differentiation condition, $B=-.18,95 \% \mathrm{CI}$ : [-.389, -.014]. ${ }^{6}$

\footnotetext{
${ }^{5}$ Please see Supplemental Materials for additional analysis of this unanticipated main effect.

${ }^{6}$ Consistent with Study 1, we tested but found no evidence for differences in knowledge hiding as a function of individuals' rank in the hierarchy. Please see Supplemental Materials for details of this analysis
} 


\section{Conditional Indirect Effects of Power Differentiation on Team Performance via Knowledge Hiding}

Mirroring past research and Study 1, knowledge hiding has a negative relationship with performance, $B=-41.22,95 \% \mathrm{CI}$ : [-75.493, -11.751]. Consistent with Hypothesis 2, status differentiation moderates the indirect effect of power differentiation on team performance via knowledge hiding, $B=-$ 19.95, 95\% CI: [-44.473, -6.469]. As predicted in Hypothesis 2a, power differentiation has a significant negative indirect effect on performance, via knowledge hiding, in the high status differentiation condition, $B=-12.55,95 \% \mathrm{CI}$ : $\quad[-30.721,-2.675]$. As predicted in Hypothesis $2 \mathrm{~b}$, power differentiation has a significant positive indirect effect on team performance in the low status differentiation condition, $B=7.40,95 \% \mathrm{CI}$ : [.873, 21.544].

Insert Figure 3 about here

\section{Discussion}

Study 2 provides causal evidence for our hypotheses that power differentiation can increase or decrease knowledge hiding, contingent on status differentiation, which, consequently, affects team performance. Consistent with Hypotheses 1a and 2a, we found that when status differentiation was high, power differentiation increased knowledge hiding and subsequently hindered team performance. This is consistent with the dysfunctional effect of power differentiation. Moreover, consistent with Hypotheses $1 \mathrm{~b}$ and $2 \mathrm{~b}$, when status differentiation was low, power differentiation decreased knowledge hiding and, as a result, improved team performance. This is consistent with the functional effect of power differentiation.

This study also provides evidence that a proactive intervention (i.e., our manipulation of low status differentiation) can decrease status differentiation, even in the presence of significant power differentiation. This is likely one of the reasons why we found support for our hypotheses ( $1 \mathrm{~b}$ and $2 \mathrm{~b})$ that power differentiation in the presence of a low level of status differentiation can be functional by decreasing knowledge hiding and improving team performance. This study therefore offers a prescription for leaders of teams as they seek to maximize team effectiveness. We elaborate on this point in the General Discussion.

Although we have so far provided robust evidence that power differentiation is dysfunctional in teams with a high degree of status differentiation, compared to teams with a low degree of status differentiation (and, indeed, can be functional in teams with status equality), we note two questions raised by our studies so far. First, our theorizing centers on status differentiation as a "switch" that determines whether power differentiation is functional or dysfunctional. Our logic hinges on the role of status differentiation in making team climates relatively more competitive (when status differentiation is high) versus cooperative (when status differentiation is low). Although we found evidence that status differentiation moderates the effect of power differentiation on knowledge hiding, our focal mechanism, we have not yet examined the role of status differentiation in shaping team climate to be more competitive versus cooperative.

Second, we note that, in Study 2, team members' power and status were aligned in the condition with both power differentiation and status differentiation. By aligned, we mean that team members' power and status were positively correlated, i.e., those who had high (or low) power also had high (or low) status. This power-status alignment reflects the reality of most teams. Empirical research that simultaneously considers power and status reports correlations between power and status ranging from +0.37 (Anicich et al. 2016) to +0.75 (Hays and Bendersky 2015). At the same time, we acknowledge that power and status hierarchies are not always in perfect alignment, as reflected in the wide range of power- 
status correlations just described. In reality, the degree of power-status alignment varies from one team to the next. ${ }^{7}$

Our theorizing predicts that teams with a high level of power differentiation and a low level of status differentiation will be more effective than will teams with high levels of both power differentiation and status differentiation. However, in teams with high levels of both power differentiation and status differentiation, we expect that the level of power-status alignment will further shape the level of knowledge hiding that occurs. ${ }^{8}$ Specifically, we predict that the knowledge hiding will be even greater in a team in which power and status are misaligned than in a team in which power and status are aligned. As the alignment between power and status decreases, the power hierarchy would less likely be seen as legitimate - defined as the belief that a hierarchy, is "appropriate, proper, and just" (Tyler 2006, p. 376). If the most powerful team members are not also high in status, they may be perceived as undeserving of their power, perhaps because they are not seen as the most competent and group-oriented team members (Anderson and Kilduff 2009). In addition to the competitive climate created by status differentiation (Hays and Bendersky 2015), team members are less likely to support an illegitimate power hierarchy (Walker et al. 1986). Moreover, team members who have high power but low status tend to exhibit toxic interpersonal behaviors (Anicich et al. 2016; Fast et al. 2012), which may further heighten the level of competition and distrust among team members.

In sum, we posit that the illegitimacy and toxic interpersonal behaviors encouraged by powerstatus misalignment in teams with both power differentiation and status differentiation present would exaggerate the competitive climate (and diminish the cooperative climate) and increase knowledge hiding among team members (Case and Maner 2014; Lammers et al. 2008). Thus, we predict:

Hypothesis 3: In teams with power differentiation and status differentiation, increasing levels of power-status misalignment will increase a) knowledge hiding and b) competitiveness, and decrease c) cooperativeness.

\section{Study 3: Exploring the Effect of Power-Status Alignment}

The purpose of Study 3 was to corroborate our theorizing that a high (vs. low) level of status differentiation makes team climates more competitive, and to examine the effect of (mis)alignment of power and status on knowledge hiding and team climate. Because the focus of our theorizing is on how the presence of power differentiation can be functional or dysfunctional, contingent on status differentiation, we have high power differentiation present in all conditions. Based on our theoretical logic and the results of Studies 1 and 2, we expect that knowledge hiding and competitiveness will be higher, and cooperativeness will be lower, in teams with status differentiation than in teams with status equality. Moreover, we expect to find that, in teams with both power differentiation and status differentiation present, increasing misalignment between power and status will further increase knowledge hiding and competitiveness, and decrease cooperativeness.

This study can also help to reconcile differences in the results of Studies 1 and 2. In Study 2,

\footnotetext{
${ }^{7}$ Importantly, power-status alignment is distinct from the degree of similarity in the levels power differentiation and status differentiation within a team. Teams can have similar or dissimilar levels of power differentiation and status differentiation regardless of the magnitude of the alignment between power and status. Consider two hypothetical teams of four in which power and status are measured on a 10-point scale. In Team A, team members' power values are 10, 7, 4 , and 1 , whereas their status values are $6,5,4$, and 3 , respectively. In this team, power and status are perfectly aligned, correlated at +1.0 , but the team has much more power differentiation $(\mathrm{CV}=.70)$ than status differentiation $(\mathrm{CV}=.29)$. In Team B, members' power values are 10, 7, 4, and 1, whereas their status values are 1, 4, 7, and 10, respectively. In this team, power and status are perfectly misaligned, correlated at -1.0 , but the team has identical levels of power differentiation $(\mathrm{CV}=.70)$ and status differentiation $(\mathrm{CV}=.70)$.

${ }^{8} \mathrm{At}$ least a moderate level of differentiation in both power and status is likely required for alignment to have an effect. If differentiation exists in power but not status (or vice versa), the concept of alignment is irrelevant. Further, a hierarchy with minimal differentiation is unlikely to be salient (Greer et al. 2017), making the degree of alignment less noticeable.
} 
there was perfect alignment between power and status in the condition with high power differentiation and high status differentiation. However, in Study 1, power-status alignment varied by team. ${ }^{9}$ To the extent that misalignment between power and status further increases knowledge hiding, the benefits of high power differentiation combined with low status differentiation may have been attenuated by imperfect alignment.

\section{Methods}

Participants and design. One hundred seventy-eight adults (31.5\% male) recruited from Prolific Academic participated in the study in exchange for $\$ 3.25$. We required that participants be native English speakers and work at least 20 hours per week to be eligible for the study. Participants averaged 34.20 years of age ( $\mathrm{SD}=9.97$ ) and 91.6 percent of the participants were Caucasian. In addition, 73.0 percent of participants held a bachelor's degree or higher, 86.1 percent of participants reported working 30 hours or more per week, on average, and the average organizational tenure was 5.02 years $(\mathrm{SD}=5.18)$.

The study had four conditions: power differentiation with status differentiation and aligned power and status hierarchies (alignment), power differentiation with status differentiation and orthogonal power and status hierarchies (orthogonal), power differentiation with status differentiation and inversely aligned power and status hierarchies (misalignment), and power differentiation with status equality (equality). Hereafter, we will refer to the conditions using the labels in parentheses.

Procedure. The study employed a fully within-subjects design, meaning that participants saw all four conditions in random order. For each condition, we asked participants to recall a past experience of working with others in a team that fit certain criteria that differed by condition (see below). In all conditions, we asked participants to recall working in a team in which some people had higher levels of power than others did (i.e., the presence of power differentiation). In addition, in the equality condition, we specified to participants that, in the team they recalled, all members should have been equally respected and held in similar esteem (i.e., status equality). We did not mention the concept of powerstatus alignment in the equality condition.

In the alignment, independent, and misalignment conditions, we specified to participants that, in the teams they recalled, some members should also have been more respected and held in higher esteem than others were (i.e., the presence of status differentiation). Further, we specified the way in which power and status were aligned in these teams. In the alignment condition, we asked participants to think of a team in which team members' level of power and status were consistent, meaning that the members who had the most power were also the most respected. In the orthogonal condition, we asked participants to think of a team in which team members' level of power and status were independent, meaning that the members who had the most power were not necessarily the most respected. Finally, in the misalignment condition, we asked participants to think of a team in which team members' level of power and status were inversely related, meaning that the members who had the most power were the least respected.

After reading the prompt for each condition, participants described their experience working in the team, including how they thought about and interacted with other members of their team. After writing about their experience with each recalled team, participants responded to a series of measures about that team on a seven-point scale ranging from 1 (strongly disagree) to 7 (strongly agree). We measured knowledge hiding using the same four-item scale $(\alpha=.92)$ as in Study 2, adapted from Connelly et al. (2012). We measured competitive and cooperative team climate using four items each $\left(\alpha_{\text {competitive }}=.91, \alpha_{\text {cooperative }}=.91\right)$ from Tjosvold and $\mathrm{Yu}(2004)$. A sample competitive climate item is "My co-workers have a 'win-lose' relationship." A sample cooperative climate item is "My co-workers and I

\footnotetext{
${ }^{9}$ We examined the role of power-status alignment in Study 1. Although the three-way interaction of power differentiation, status differentiation, and power-status alignment was non-significant, this is likely due to a lack of sufficient statistical power to detect a three-way interaction. However, the pattern of results was consistent with our theorizing about the role of alignment. Please see the Supplemental Materials for details of this analysis.
} 
want each other to succeed."

\section{Results}

Table 1c includes descriptive statistics and correlations between variables. Because of the withinsubjects study design, we analyzed the data using mixed-effects regression models with condition nested within participants. We examine the effects of condition, order, and their interaction on all outcome variables. We provide ANOVA-style results for ease of interpretation.

Knowledge Hiding. Mixed-effects regression revealed a significant main effect of condition $\left(\chi^{2}(3)=52.57, p<.001\right)$, an unexpected significant main effect of order $\left(\chi^{2}(3)=10.42, p=.015\right)^{10}$, but no significant interaction of condition and order $\left(\chi^{2}(9)=10.52, p=.310\right)$. As expected, participants reported lower levels of knowledge hiding in the equality condition $(M=1.88, S D=1.16)$ than in the alignment condition $(M=2.29, S D=1.44), \chi^{2}(1)=14.57, p<.001$, the orthogonal condition $(M=2.45, S D=1.38)$, $\chi^{2}(1)=35.16, p<.001$, and the misalignment condition $(M=2.52, S D=1.38), \chi^{2}(1)=42.71, p<.001$ (see Figure 4a). Consistent with our theorizing and the prior studies, these results indicate that knowledge hiding is lower when power differentiation is combined with status equality than when it is combined with status differentiation.

Turning to the effects of power-status alignment within teams that have both power differentiation and status differentiation, participants reported lower levels of knowledge hiding in the alignment condition than in the orthogonal condition, $\chi^{2}(1)=4.33, p=.038$, and the misalignment condition, $\left.\chi^{2}(1)=7.17, p=.007\right)$. The misalignment condition did not differ from the orthogonal condition, $\chi^{2}(1)=.36, p=.550$. These results support our prediction that knowledge hiding increases as power-status alignment decreases.

Competitive Climate. Mixed-effects regression revealed a significant main effect of condition $\left(\chi^{2}(3)=130.17, p<.001\right)$, no significant main effect of $\operatorname{order}\left(\chi^{2}(3)=.87, p=.832\right)$, and a marginally significant interaction of condition and order $\left(\chi^{2}(9)=15.49, p=.078\right)$. As expected, participants reported less competitive team climates in the equality condition $(M=2.92, S D=1.50)$ than in the alignment condition $(M=3.45, S D=1.65), \chi^{2}(1)=14.82, p<.001$, the orthogonal condition $(M=4.06, S D=1.59)$, $\chi^{2}(1)=69.90, p<.001$, and the misalignment condition $(M=4.36, S D=1.41), \chi^{2}(1)=108.12, p<.001$ (see Figure $4 \mathrm{~b}$ ). This supports our theorizing that teams with power differentiation combined with status differentiation have more competitive team climates than do teams with power differentiation combined with status equality.

Turning to the effects of power-status alignment within teams that have both power differentiation and status differentiation, participants reported less competitive climates in the alignment condition than in the orthogonal condition, $\chi^{2}(1)=19.90, p<.001$, and the misalignment condition, $\chi^{2}(1)$ $=42.00, p<.001$. In addition, participants reported less competitive climates in the orthogonal condition than in the misalignment condition, $\chi^{2}(1)=4.09, p=.043$. These results indicate that team climates become more competitive as power-status alignment decreases, as expected.

Cooperative Climate. Mixed-effects regression revealed a significant main effect of condition $\left(\chi^{2}(3)=138.28, p<.001\right)$, a marginally significant main effect of order $\left(\chi^{2}(3)=6.31, p=.097\right)$, and a

\footnotetext{
${ }^{10}$ Although not expected, participants reported increasing levels of knowledge hiding as they proceeded through the four conditions, independent of condition. Knowledge hiding did not differ between the first $(M=2.14, S D=1.18)$ and second $(M=2.23, S D=1.28)$ conditions presented, $\chi^{2}(1)=.58, p=.447$, between the second and third $(M=2.38, S D$ $=1.53)$ conditions presented, $\chi^{2}(1)=2.18, p=.140$, or between the third and fourth $(M=2.40, S D=1.43)$ conditions presented, $\chi^{2}(1)=.39, p=.530$. However, participants reported lower levels of knowledge hiding in the first condition than in the third condition presented, $\chi^{2}(1)=5.04, p=.025$, between the first and fourth conditions presented, $\chi^{2}(1)=$ $8.15, p=.004$, and between the second and fourth conditions presented, $\chi^{2}(1)=4.37, p=.037$.
} 
marginally significant interaction of condition and order $\left(\chi^{2}(9)=16.74, p=.053\right)$. In contrast to the results for our measure of competitive climate, participants reported more cooperative climates in the equality condition $(M=5.64, S D=1.15)$ than in the alignment condition $(M=5.25, S D=1.32), \chi^{2}(1)=$ $10.67, p=.001$, the orthogonal condition $(M=4.60, S D=1.39), \chi^{2}(1)=74.00, p<.001$, and the misalignment condition $(M=4.36, S D=1.48), \chi^{2}(1)=108.84, p<.001$ (see Figure $4 \mathrm{c}$ ). Together, the results support our theorizing that teams with power differentiation combined with status differentiation have less cooperative (and more competitive) team climates than do teams with power differentiation combined with status equality.

Within teams that have both power differentiation and status differentiation, participants reported more cooperative climates in the alignment condition than in the orthogonal condition, $\chi^{2}(1)=27.90, p<$ .001 , and in the misalignment condition, $\chi^{2}(1)=50.38, p<.001$. In addition, participants reported marginally more cooperative climates in the orthogonal condition than in the misalignment condition, $\chi^{2}(1)=3.30, p=.069$. Thus, as expected, team climates become less cooperative as power-status alignment decreases.

Insert Figure 4 about here

\section{Discussion}

This study provides evidence that the presence of a high (versus low) level of status differentiation shapes a team's climate to be more competitive and less cooperative. This effect is central to our arguments about why status differentiation serves as a "switch" that makes power differentiation either functional or dysfunctional. Moreover, as expected, we found that knowledge hiding increases, and team climates become more competitive and less cooperative, as the alignment of power and status within teams declines.

\section{General Discussion}

The question of whether hierarchy is functional or dysfunctional for teams has long perplexed scholars. Building on recent evidence that power and status are distinct and can have interactive psychological effects on individuals, we argue that power differentiation and status differentiation can also have interactive effects on teams. We find consistent evidence that the effects of power differentiation on knowledge hiding and team performance are contingent on status differentiation. In Study 1, power differentiation was dysfunctional in teams with a high level of status differentiation by increasing knowledge hiding and harming performance. We did not find evidence that power differentiation could be functional by reducing knowledge hiding in teams with low status differentiation, likely because power differentiation and status differentiation were positively correlated. In Study 2, we tested an intervention intended to reduce status differentiation. We found that power differentiation was functional in teams with low status differentiation by reducing knowledge hiding and improving performance, as we expected, and we replicated the dysfunctional effect of power differentiation found in Study 1 in teams with high status differentiation.

Lastly, we examined the effect of status differentiation on team climate, and the effects of powerstatus alignment in Study 3. We found that status differentiation makes team climates more competitive and less cooperative, compared to teams with status equality. This is consistent with our theorizing that status differentiation serves as a "switch" that makes power differentiation functional or dysfunctional by heightening a sense of competitiveness in teams. We also found that, in teams with high levels of power differentiation and status differentiation, misalignment between power and status within these teams exacerbates knowledge hiding, and increases the competitiveness and decreases the cooperativeness of the team climate. Thus, our research addresses calls from hierarchy scholars to shed light on hierarchy 
functionality (Anderson and Brown 2010; Sturm and Antonakis 2015) and highlights the importance of taking a nuanced approach to considering how team structure can affect team dynamics and effectiveness.

\section{Theoretical Contributions}

This research makes several contributions to our understanding of hierarchy. First, this work helps to reconcile the functional and dysfunctional accounts of hierarchy. Both of these accounts are supported by theorizing and empirical evidence, leading to efforts to understand the conditions under which hierarchy helps versus harms teams. We highlight that the basis of hierarchical differentiation can determine whether hierarchical differentiation is functional versus dysfunctional by attenuating or exaggerating self-interested knowledge hiding behaviors that undermine the work of the team. Our research indicates that when members are differentiated in both power and status, team performance is likely to suffer as members hide their knowledge and perspectives from each other. However, in teams where everyone is respected relatively equally, power differentiation can reduce knowledge hiding, which benefits team performance.

We note, however, that power differentiation and status differentiation were positively correlated in Study 1, which is one likely reason why power differentiation was never functional in this study. This suggests that teams with high power differentiation may naturally drift toward also having high status differentiation in the absence of proactive efforts to reduce status differentiation. This may also explain why a recent meta-analysis (Greer et al. 2018) found high variability in the relationship between hierarchical differentiation and performance but, overall, a small, significant negative relationship. We hope that the intervention we tested in Study 2 to reduce status differentiation will be helpful by showing how teams can realize benefits of hierarchy while minimizing its costs. Given the ubiquity of hierarchy in all social settings, understanding the conditions under which differentiation is beneficial holds enormous value for social hierarchy and teams researchers.

Second, we contribute to a growing body of research that highlights important differences between power and status. We show that, at the team level, power differentiation and status differentiation are distinct and have interactive consequences for teams. Our research also highlights the importance of examining power and status at the team level. Individual-level effects of power and status do not directly translate to the team level because teams involve interactions between people who differ in power and status (Greer et al. 2017). For example, Galinsky et al. (2014) found that high power combined with perspective-taking, which is associated with high status (Blader et al. 2016), increased information sharing among individuals. In contrast, our research indicates that high power differentiation combined with high status differentiation increases the tendency to hide rather than share information within teams. We encourage scholars to investigate other ways that constructs such as power and status have distinct effects at the individual versus at the team level.

Third, we disentangle power differentiation and status differentiation but examine how they operate in tandem, as they typically exist in organizations. In doing so, we find that power differentiation can be helpful as long as status differentiation is minimized. In some ways, our findings mirror research on team demographic diversity (e.g., gender, race, etc.), which can have positive or negative effects on team performance (e.g., Guzzo and Dickson 1996; Milliken and Martins 1996; Williams and O'Reilly 1998). Team diversity can be dysfunctional when more versus less valued social categories (e.g., Whites versus Blacks, doctors versus nurses, etc.) are salient, which creates status differentiation that heightens members' prioritization of self-interests over those of the group and reduces information exchange (Jehn et al. 1999; Murnighan and Conlon 1991; Simons et al. 1999). However, when social categories are not salient and members have equal status, competitive tendencies are reduced. In this environment, diversity can improve team performance by providing access to more information (Bantel and Jackson 1989; Cox et al. 1991; Jehn et al. 1999) and improving the integration of information among team members (Hinsz et al. 1997; Homan et al. 2007; van Knippenberg et al. 2004). Just as power differentiation can be functional or dysfunctional, contingent upon status differentiation, whether diversity is functional or dysfunctional 
for team performance depends on whether people with diverse characteristics and perspectives are equally valued.

Finally, we highlight the effects of alignment between teams' power and status hierarchies on the team climate and knowledge hiding behavior. Although power and status tend to be positively correlated in real-world settings (Kennedy and Anderson 2017; Yu et al. 2019), this correlation varies substantially. However, we are unaware of research that has examined the effects of power-status alignment in teams. We find that misalignment between power and status and increases knowledge hiding, heightens competitiveness, and decreases cooperativeness in the team climate. We encourage more research to distinguish between power and status but examine them in tandem, exploring the effects of within-team alignment between these two hierarchies on team processes and outcomes.

\section{Practical Implications}

Our research has a variety of practical implications for constructing teams. Our findings suggest that the rush to abandon hierarchy may be "throwing the baby out with the bathwater." Hierarchy can have a number of important benefits that allow collectives to function, which is likely why hierarchy exists in all types of settings and has persisted over time. To the extent that organizations and collectives can maintain these benefits while minimizing dysfunctional conflict and competition among their members, they are likely to outperform groups that cannot strike this balance. The present research suggests that one way of maximizing the value of hierarchy is to allow differentiation based on decisionmaking authority and control over resources (i.e., high power differentiation) but ensure that all members are respected relatively equally regardless of their role or rank in the organization (i.e., low status differentiation).

Our work also highlights the importance of leaders in minimizing status differentiation. The positive correlation between power differentiation and status differentiation in Study 1 and the effect of our power manipulation on status differentiation scores in Study 2 suggest that having differentiation in power but not in status may not occur naturally or easily. Creating an environment with minimal status differentiation requires proactive effort and, most likely, ongoing reinforcement and maintenance. The intervention we tested in Study 2 to minimize status differentiation indicates that this is possible. However, team leaders need to be explicit and assertive in reminding team members that, despite different roles, responsibilities, and levels of authority, all team members are vital to accomplishing team goals and, therefore, deserve equal respect.

\section{Directions for Future Research}

Our research answers important questions about the functionality of hierarchy, but also raises several new questions that we hope will stimulate future research. First, although power differentiation and status differentiation interactively affected knowledge hiding and team performance in two studies, the nature of the interactions differed somewhat. Specifically, power differentiation in teams with a high level of status differentiation was detrimental in both studies, but power differentiation in teams with a low level of status differentiation was beneficial in only one study (Study 2). We speculate that this difference is due to the positive correlation of power differentiation and status differentiation and greater variance in power-status alignment in Study 1, but this is ultimately an empirical question. Differences in the type of task may have also played a role. Although the tasks we used in both studies were interdependent in nature, which benefit from hierarchy (Halevy et al. 2011a; Ronay et al. 2012), the task in Study 2 was more structured (while still complex) as teams attempted to converge on a correct solution, whereas the tasks undertaken by the teams in Study 1 were less structured, involved greater creativity, and had no single "right answer." This is consistent with past research indicating that hierarchy is more helpful for idea selection than for idea generation (Keum and See 2017). Future research should examine the effects of these possible moderators more directly. 
More broadly, we encourage future research to consider other factors that may further moderate the interaction of power differentiation and status differentiation. Past research suggests that the functionality of various team structures is contingent on many factors, including how work is divided (Becker and Baloff 1969), the type of feedback provided (Van der Vegt et al. 2010), the nature of outcome (Anicich et al. 2015), and the average level of power within a team (Greer and van Kleef 2010). Perhaps the benefits of power differentiation that we observe in Study 2 rely on all team members being equal and high in status. Moreover, researchers should investigate whether power differentiation and status differentiation have the same effects in virtual teams as in the face-to-face teams we studied here. This is particularly important because the trend toward telecommuting was significantly expedited by the recent coronavirus pandemic. Perhaps the effects of status differentiation are attenuated in virtual environments because the experience of having high or low status matters less without the rich social cues provided through face-to-face interaction (Weisband et al. 1995). We encourage future research to consider whether the basis of differentiation interacts with a variety of moderators, including those examined in past research.

Second, we examined knowledge hiding as our focal mechanism because of the interdependent nature of the task. Future research should also examine other mechanisms, and in particular, motivationrelated mechanisms (e.g., effort). Although status differentiation can create a competitive climate that is dysfunctional, status differentiation may be beneficial if the hierarchy is highly meritocratic, with rank based solely on output that benefits the group. For example, if status is tied to revenue generation within a sales team, the competition engendered by status differentiation could benefit the team as individual salespeople attempt to outsell each other, even though their desire for status is self-interested.

Finally, we call for additional research on how the alignment between power and status in a team predicts team processes and performance. In addition to the effects of alignment we found in Study 3 , researchers have also found that power differentiation benefits team performance when people's power and task competence are aligned, and harms team performance when they are not (Tarakci et al. 2016). We examined the effects of power and status alignment on knowledge hiding and team climate but there are many other potential consequences of alignment for team processes and outcomes. How the alignment between power and status in a team influences team processes and performance is a theoretically valuable question that we encourage researchers to examine more carefully in the future.

\section{Conclusion}

The inconsistent effects of hierarchy on performance documented in past research have limited our understanding of a ubiquitous and fundamental feature of social life. We examine effects of specific bases of hierarchical differentiation on individuals' behavior and team performance. We find that power differentiation can be either functional or dysfunctional, contingent on status differentiation. Moreover, when both power differentiation and status differentiation are present, the alignment of the power and status hierarchies also shapes team interactions. We hope that our work sheds light on the functionality of hierarchy for teams and is instructive for practitioners who create and manage teams. 


\section{References}

Amabile, T., C.M. Fisher, J. Pillemer. 2014. Ideo's culture of helping. Harvard Business Review 92(1-2) 54.

Anderson, C., C.E. Brown. 2010. The functions and dysfunctions of hierarchy. Research in Organizational Behavior 30 55-89.

Anderson, C., J.A.D. Hildreth, L. Howland. 2015. Is the desire for status a fundamental human motive? A review of the empirical literature. Psychol. Bull. 141(3) 574-601.

Anderson, C., O.P. John, D. Keltner, A.M. Kring. 2001. Who attains social status? Effects of personality and physical attractiveness in social groups. J. Pers. Soc. Psychol. 81(1) 116-132.

Anderson, C., G.J. Kilduff. 2009. The pursuit of status in social groups. Current Directions in Psychological Science 18(5) 295-298.

Anderson, C., S. Srivastava, J.S. Beer, S.E. Spataro, J.A. Chatman. 2006. Knowing your place: Self-perceptions of status in face-to-face groups. J. Pers. Soc. Psychol. 91(6) 1094-1110.

Anicich, E.M., N.J. Fast, N. Halevy, A.D. Galinsky. 2016. When the bases of social hierarchy collide: Power without status drives interpersonal conflict. Organ Sci. 27(1) 123-140.

Anicich, E.M., R.I. Swaab, A.D. Galinsky. 2015. Hierarchical cultural values predict success and mortality in highstakes teams. Proc. Natl. Acad. Sci. U. S. A. 112(5) 1338-1343.

Bantel, K.A., S.E. Jackson. 1989. Top management and innovations in banking - does the composition of the top team make a difference. Strateg. Manage. J. 10 107-124.

Becker, S.W., N. Baloff. 1969. Organization structure and complex problem solving. Adm. Sci. Q. 14(2) 260-271.

Bendersky, C., N.A. Hays. 2012. Status conflict in groups. Organ Sci. 23(2) 323-340.

Berger, J., B.P. Cohen, M. Zelditch. 1972. Status characteristics and social interaction. Am. Sociol. Rev. 37(3) 241255.

Berkowitz, L., E. Donnerstein. 1982. External validity is more than skin deep - some answers to criticisms of laboratory experiments. Am. Psychol. 37(3) 245-257.

Blader, S.L., Y.R. Chen. 2012. Differentiating the effects of status and power: A justice perspective. J. Pers. Soc. Psychol. 102(5) 994-1014.

Blader, S.L., Y.R. Chen. 2014. What's in a name? Status, power, and other forms of social hierarchy. J.T. Cheng, J.L. Tracy, C. Anderson, eds. The psychology of social status. Springer New York, 71-95.

Blader, S.L., A. Shirako, Y.R. Chen. 2016. Looking out from the top: Differential effects of status and power on perspective taking. Pers. Soc. Psychol. Bull. 42(6) 723-737.

Blau, P.M. 1964. Exchange and power in social life. John Wiley, New York.

Bunderson, J.S., R.E. Reagans. 2011. Power, status, and learning in organizations. Organ Sci. 22(5) 1182-1194.

Carzo, R., J.N. Yanouzas. 1969. Effects of flat and tall organization structure. Adm. Sci. Q. 14(2) 178-191.

Case, C.R., K.K. Bae, J.K. Maner. 2018. To lead or to be liked: When prestige-oriented leaders prioritize popularity over performance. J. Pers. Soc. Psychol. 115(4) 657-676.

Case, C.R., J.K. Maner. 2014. Divide and conquer: When and why leaders undermine the cohesive fabric of their group. J. Pers. Soc. Psychol. 107(6) 1033-1050.

Cerne, M., C.G.L. Nerstad, A. Dysvik, M. Skerlavaj. 2014. What goes around comes around: Knowledge hiding, perceived motivational climate, and creativity. Acad. Manage. J. 57(1) 172-192.

Chan, D. 1998. Functional relations among constructs in the same content domain at different levels of analysis: A typology of composition models. J. Appl. Psychol. 83(2) 234-246.

Chen, S., A.Y. Lee-Chai, J.A. Bargh. 2001. Relationship orientation as a moderator of the effects of social power. $J$. Pers. Soc. Psychol. 80(2) 173-187. 
Colquitt, J.A. 2008. Publishing laboratory research in amj: A question of when, not if. Acad. Manage. J. 51(4) 616620.

Connelly, C.E., D. Zweig, J. Webster, J.P. Trougakos. 2012. Knowledge hiding in organizations. Journal of Organizational Behavior 33(1) 64-88.

Cox, T.H., S.A. Lobel, P.L. McLeod. 1991. Effects of ethnic-group cultural-differences on cooperative and competitive behavior on a group task. Acad. Manage. J. 34(4) 827-847.

Cunningham, J.L., F. Gino, D.M. Cable, B.R. Staats. in press. Seeing oneself as a valued contributor: Social worth affirmation improves team information sharing. Acad. Manage. J.

De Cremer, D., E. Van Dijk. 2005. When and why leaders put themselves first: Leader behaviour in resource allocations as a function of feeling entitled. Eur. J. Soc. Psychol. 35(4) 553-563.

De Cremer, D., D. van Knippenberg. 2002. How do leaders promote cooperation? The effects of charisma and procedural fairness. J. Appl. Psychol. 87(5) 858-866.

DeCelles, K.A., D.S. DeRue, J.D. Margolis, T.L. Ceranic. 2012. Does power corrupt or enable? When and why power facilitates self-interested behavior. J. Appl. Psychol. 97(3) 681-689.

Deci, E.L., R.M. Ryan. 1987. The support of autonomy and the control of behavior. J. Pers. Soc. Psychol. 53(6) 1024-1037.

DeRue, D.S., S.J. Ashford. 2010. Who will lead and who will follow? A social process of leadership identity construction in organizations. Acad. Manage. Rev. 35(4) 627-647.

Dionne, S.D., F.J. Yammarino, L.E. Atwater, W.D. Spangler. 2004. Transformational leadership and team performance. Journal of Organizational Change Management 17(2) 177-193.

Dornbusch, S.M., W.R. Scott. 1975. Evaluation and the exercise of authority: A theory of control applied to diverse organizations. Jossey-Bass, San Francisco.

Dubois, D., D.D. Rucker, A.D. Galinsky. 2012. Super size me: Product size as a signal of status. J. Consum. Res. 38(6) 1047-1062.

Emerson, R.M. 1962. Power-dependence relations. Am. Sociol. Rev. 27(1) 31-41.

Evans, J.M., M.G. Hendron, J.B. Oldroyd. 2015. Withholding the ace: The individual- and unit-level performance effects of self-reported and perceived knowledge hoarding. Organ Sci. 26(2) 494-510.

Fast, N.J., N. Halevy, A.D. Galinsky. 2012. The destructive nature of power without status. Journal of Experimental Social Psychology 48(1) 391-394.

Fiske, S.T. 2010. Interpersonal stratification: Status, power, and subordination. S.T. Fiske, D.T. Gilbert, G. Lindzey, eds. Handbook of social psychology, 5th ed. John Wiley \& Sons Inc, Hoboken, NJ, 941-982.

French, J.R.P., Jr., B. Raven. 1959. The bases of social power. D. Cartwright, ed. Studies in social power. University of Michigan Press, Ann Arbor, MI, 150-167.

Galinsky, A.D., J.C. Magee, M.E. Inesi, D.H. Gruenfeld. 2006. Power and perspectives not taken. Psychol. Sci. 17(12) 1068-1074.

Galinsky, A.D., J.C. Magee, D. Rus, N.B. Rothman, A.R. Todd. 2014. Acceleration with steering: The synergistic benefits of combining power and perspective-taking. Social Psychological and Personality Science 5(6) 627635.

Gardner, H.K., F. Gino, B.R. Staats. 2012. Dynamically integrating knowledge in teams: Transforming resources into performance. Acad. Manage. J. 55(4) 998-1022.

Georgesen, J.C., M.J. Harris. 2000. The balance of power: Interpersonal consequences of differential power and expectancies. Pers. Soc. Psychol. Bull. 26(10) 1239-1257.

Greer, L.L., B.A. de Jong, M.E. Schouten, J.E. Dannals. 2018. Why an when hierarchy impacts team effectiveness: A meta-analytic integration. J. Appl. Psychol. 103(6) 591-613. 
Greer, L.L., L. Van Bunderen, S.Y. Yu. 2017. The dysfunctions of power in teams: A review and emergent conflict perspective. B.M. Staw, A.P. Brief, eds. Research in organizational behavior: An annual series of analytical essays and critical reviews, vol 37. Elsevier, New York, 103-124.

Greer, L.L., G.A. van Kleef. 2010. Equality versus differentiation: The effects of power dispersion on group interaction. J. Appl. Psychol. 95(6) 1032-1044.

Guinote, A. 2007. Power and goal pursuit. Pers. Soc. Psychol. Bull. 33(8) 1076-1087.

Guzzo, R.A., M.W. Dickson. 1996. Teams in organizations: Recent research on performance and effectiveness. Annu. Rev. Psychol. 47 307-338.

Haas, M.R., S. Park. 2010. To share or not to share? Professional norms, reference groups, and information withholding among life scientists. Organ Sci. 21(4) 873-891.

Halevy, N., E.Y. Chou, A.D. Galinsky. 2011a. A functional model of hierarchy. Organizational Psychology Review 1(1) $32-52$.

Halevy, N., E.Y. Chou, A.D. Galinsky, J.K. Murnighan. 2011b. When hierarchy wins: Evidence from the national basketball association. Social Psychological and Personality Science.

Harrison, D.A., K.J. Klein. 2007. What's the difference? Diversity constructs as separation, variety, or disparity in organizations. Acad. Manage. Rev. 32(4) 1199-1228.

Hays, N.A. 2013. Fear and loving in social hierarchy: Sex differences in preferences for power versus status. Journal of Experimental Social Psychology 49(6) 1130-1136.

Hays, N.A., C. Bendersky. 2015. Not all inequality is created equal: Effects of status versus power hierarchies on competition for upward mobility. J. Pers. Soc. Psychol. 108(6) 867-882.

Hays, N.A., S.L. Blader. 2017. To give or not to give? Interactive effects of status and legitimacy on generosity. $J$. Pers. Soc. Psychol. 112(1) 17-38.

Hinsz, V.B., R.S. Tindale, D.A. Vollrath. 1997. The emerging conceptualization of groups as information processors. Psychol. Bull. 121(1) 43-64.

Hollenbeck, J.R., B. Beersma, M.E. Schouten. 2012. Beyond team types and taxonomies: A dimensional scaling conceptualization for team description. Acad. Manage. Rev. 37(1) 82-106.

Homan, A.C., D. van Knippenberg, G.A. Van Kleef, C.K.W. De Dreu. 2007. Bridging faultlines by valuing diversity: Diversity beliefs, information elaboration, and performance in diverse work groups. J. Appl. Psychol. 92(5) 1189-1199.

Humphrey, R. 1985. How work roles influence perception - structural-cognitive processes and organizationalbehavior. Am. Sociol. Rev. 50(2) 242-252.

Ilgen, D.R. 1985. Laboratory research: A question of when, not if. E.A. Locke, ed. The generalizability of laboratory experiments: An inductive survey. Heath, Lexington, MA, 257-267.

Ilgen, D.R., J.R. Hollenbeck, M. Johnson, D. Jundt. 2005. Teams in organizations: From input-process-output models to imoi models. Annu. Rev. Psychol. 56 517-543.

Inesi, M.E., D.H. Gruenfeld, A.D. Galinsky. 2012. How power corrupts relationships: Cynical attributions for others' generous acts. Journal of Experimental Social Psychology 48(4) 795-803.

Jehn, K.A., G.B. Northcraft, M.A. Neale. 1999. Why differences make a difference: A field study of diversity, conflict, and performance in workgroups. Adm. Sci. Q. 44 741-763.

Jensen, M., H. Kim. 2015. The real oscar curse: The negative consequences of positive status shifts. Organ Sci. 26(1) $1-21$.

Keltner, D., D.H. Gruenfeld, C. Anderson. 2003. Power, approach, and inhibition. Psychol. Rev. 110(2) 265-284.

Kemper, T.D., R. Collins. 1990. Dimensions of microinteraction. Am. J. Sociol. 96(1) 32-68.

Kennedy, J.A., C. Anderson. 2017. Hierarchical rank and principled dissent: How holding higher rank suppresses 
objection to unethical practices. Organizational Behavior and Human Decision Processes 139 30-49.

Keum, D.D., K.E. See. 2017. The influence of hierarchy on idea generation and selection in the innovation process. Organ Sci. 28(4) 653-669.

Kipnis, D. 1972. Does power corrupt? J. Pers. Soc. Psychol. 24(1) 33-41.

Kozlowski, S.W.J., B.S. Bell. 2013. Work groups and teams in organizations: Review update. N. Schmitt, S. Highhouse, eds. Handbook of psychology: Industrial and organizational psychology, 2nd ed. Wiley, Hoboken, NJ, 412-469.

Lam, B. (2016). Why are so many zappos employees leaving? The Atlantic.

Lam, S.S.K., J. Schaubroeck. 2000. Improving group decisions by better pooling information: A comparative advantage of group decision support systems. J. Appl. Psychol. 85(4) 565-573.

Lammers, J., A.D. Galinsky, E.H. Gordijn, S. Otten. 2008. Illegitimacy moderates the effects of power on approach. Psychol. Sci. 19(6) 558-564.

Lee, S.M., J. Koopman, J.R. Hollenbeck, L.C. Wang, K. Lanaj. 2015. The team descriptive index (tdi): A multidimensional scaling approach for team description. Academy of Management Discoveries 1(1) 91-116.

Li, H., Y.C. Yuan, N.N. Bazarova, B.S. Bell. 2018. Talk and let talk: The effects of language proficiency on speaking up and competence perceptions in multinational teams. Group \& Organization Management.

Lorinkova, N.M., M.J. Pearsall, H.P. Sims. 2013. Examining the differential longitudinal performance of directive versus empowering leadership in teams. Acad. Manage. J. 56(2) 573-596.

Magee, J.C., A.D. Galinsky. 2008. Social hierarchy: The self-reinforcing nature of power and status. The Academy of Management Annals 2 351-398.

Magee, J.C., C.A. Langner. 2008. How personalized and socialized power motivation facilitate antisocial and prosocial decision-making. J. Res. Pers. 42(6) 1547-1559.

Maner, J.K., N.L. Mead. 2010. The essential tension between leadership and power: When leaders sacrifice group goals for the sake of self-interest. J. Pers. Soc. Psychol. 99(3) 482-497.

March, J.G., H.A. Simon. 1958. Organizations. Wiley and Sons, New York.

McClelland, D.C. 1970. The two faces of power. Journal of International Affairs 24(1) 29-47.

Mesmer-Magnus, J.R., L.A. DeChurch. 2009. Information sharing and team performance: A meta-analysis. J. Appl. Psychol. 94(2) 535-546.

Milliken, F.J., L.L. Martins. 1996. Searching for common threads: Understanding the multiple effects of diversity in organizational groups. Acad. Manage. Rev. 21(2) 402-433.

Murnighan, J.K., D.E. Conlon. 1991. The dynamics of intense work groups - a study of british string-quartets. Adm. Sci. Q. 36(2) 165-186.

Pettit, N.C., N. Sivanathan. 2012. The eyes and ears of status: How status colors perceptual judgment. Pers. Soc. Psychol. Bull. 38(5) 570-582.

Pitesa, M., S. Thau. 2013. Compliant sinners, obstinate saints: How power and self-focus determine the effectiveness of social influences in ethical decision making. Acad. Manage. J. 56(3) 635-658.

Podolny, J.M. 1993. A status-based model of market competition. Am. J. Sociol. 98(4) 829-872.

Postmes, T., R. Spears, S. Cihangir. 2001. Quality of decision making and group norms. J. Pers. Soc. Psychol. 80(6) 918-930.

Ridgeway, C.L., D. Diekema. 1989. Dominance and collective hierarchy formation in male and female task groups. Am. Sociol. Rev. 54(1) 79-93.

Roberson, Q.M., M.C. Sturman, T.L. Simons. 2007. Does the measure of dispersion matter in multilevel research? A comparison of the relative performance of dispersion indexes. Organ. Res. Methods 10(4) 564-588. 
Ronay, R., K. Greenaway, E.M. Anicich, A.D. Galinsky. 2012. The path to glory is paved with hierarchy. Psychol. Sci. 23(6) 669-677.

Rucker, D.D., A.D. Galinsky. 2008. Desire to acquire: Powerlessness and compensatory consumption. J. Consum. Res. 35(2) 257-267.

Sande, G.N., J.H. Ellard, M. Ross. 1986. Effect of arbitrarily assigned status labels on self-perceptions and social perceptions - the mere position effect. J. Pers. Soc. Psychol. 50(4) 684-689.

Schneider, B., M.G. Ehrhart, W.H. Macey. 2013. Organizational climate and culture. S.T. Fiske, ed. Annual review of psychology, vol 64. Annual Reviews, Palo Alto, 361-388.

See, K.E., E.W. Morrison, N.B. Rothman, J.B. Soll. 2011. The detrimental effects of power on confidence, advice taking, and accuracy. Organizational Behavior and Human Decision Processes 116(2) 272-285.

Simons, T., L.H. Pelled, K.A. Smith. 1999. Making use of difference: Diversity, debate, and decision comprehensiveness in top management teams. Acad. Manage. J. 42(6) 662-673.

Sleesman, D.J., J.R. Hollenbeck, M. Spitzmuller, M.E. Schouten. 2018. Initial expectations of team performance: Specious speculation or framing the future? Small Group Research 49(5) 600-635.

Strauss, A., L. Schatzman, D. Ehrlich, R. Bucher, M. Sabshin. 1963. The hospital and its negotiated order. E. Freidson, ed. The hospital in modern society. Free Press, New York, 147-169.

Sturm, R.E., J. Antonakis. 2015. Interpersonal power: A review, critique, and research agenda. J. Manag. 41(1) 136163.

Sutton, R.I., A. Hargadon. 1996. Brainstorming groups in context: Effectiveness in a product design firm. Adm. Sci. Q. 41(4) 685-718.

Tarakci, M., L.L. Greer, P.J.F. Groenen. 2016. When does power disparity help or hurt group performance? J. Appl. Psychol. 101(3) 415-429.

Tiedens, L.Z., A.R. Fragale. 2003. Power moves: Complementarity in dominant and submissive nonverbal behavior. J. Pers. Soc. Psychol. 84(3) 558-568.

Tiedens, L.Z., M.M. Unzueta, M.J. Young. 2007. An unconscious desire for hierarchy? The motivated perception of dominance complementarity in task partners. J. Pers. Soc. Psychol. 93(3) 402-414.

Tiwana, A., M. Keil. 2007. Does peripheral knowledge complement control? An empirical test in technology outsourcing alliances. Strateg. Manage. J. 28(6) 623-634.

Tjosvold, D., Z.Y. Yu. 2004. Goal interdependence and applying abilities for team in-role and extra-role performance in china. Group Dyn.-Theory Res. Pract. 8(2) 98-111.

Torrance, E.P. 1955. Some consequences of power differences on decision making in permanent and temporary three-man groups. A.P. Hare, E.F. Borgatta, R.F. Bales, eds. Small groups: Studies in social interaction. Knopf, New York.

Tost, L.P., F. Gino, R.P. Larrick. 2012. Power, competitiveness, and advice taking: Why the powerful don't listen. Organizational Behavior and Human Decision Processes 117(1) 53-65.

Tost, L.P., F. Gino, R.P. Larrick. 2013. When power makes others speechless: The negative impact of leader power on team performance. Acad. Manage. J. 56(5) 1465-1486.

Tyler, T.R. 2002. Leadership and cooperation in groups. Am. Behav. Sci. 45(5) 769-782.

Tyler, T.R. 2006. Psychological perspectives on legitimacy and legitimation. Annu. Rev. Psychol. 57 375-400.

Tyler, T.R., S.L. Blader. 2003. The group engagement model: Procedural justice, social identity, and cooperative behavior. Personality and Social Psychology Review 7(4) 349-361.

Van Bunderen, L., L.L. Greer, D. Van Knippenberg. 2018. When interteam conflict spirals into intrateam power struggles: The pivotal role of team power structures. Acad. Manage. J. 61(3) 1100-1130.

Van der Vegt, G.S., S.B. de Jong, J.S. Bunderson, E. Molleman. 2010. Power asymmetry and learning in teams: The 
moderating role of performance feedback. Organ Sci. 21(2) 347-361.

van Knippenberg, D., C.K.W. De Dreu, A.C. Homan. 2004. Work group diversity and group performance: An integrative model and research agenda. J. Appl. Psychol. 89(6) 1008-1022.

Van Vugt, M. 2006. Evolutionary origins of leadership and followership. Personality and Social Psychology Review 10(4) 354-371.

Van Vugt, M., R. Hogan, R.B. Kaiser. 2008. Leadership, followership, and evolution - some lessons from the past. Am. Psychol. 63(3) 182-196.

Walker, H.A., G.M. Thomas, M. Zelditch. 1986. Legitimation, endorsement, and stability. Soc. Forces 64(3) 620643.

Weisband, S.P., S.K. Schneider, T. Connolly. 1995. Computer-mediated communication and social information status salience and status differences. Acad. Manage. J. 38(4) 1124-1151.

Williams, K.Y., C.A. O'Reilly. 1998. Demography and diversity in organizations: A review of 40 years of research. Research in Organizational Behavior 20 77-140.

Williamson, O.E. 1981. The economics of organization: The transaction cost approach. Am. J. Sociol. 87(3) 548577.

Wittenbaum, G.M., A.B. Hollingshead, I.C. Botero. 2004. From cooperative to motivated information sharing in groups: Moving beyond the hidden profile paradigm. Commun. Monogr. 71(3) 286-310.

Woolley, A.W., C.F. Chabris, A. Pentland, N. Hashmi, T.W. Malone. 2010. Evidence for a collective intelligence factor in the performance of human groups. Science 330(6004) 686-688.

Wright, S.C. 1997. Ambiguity, social influence, and collective action: Generating collective protest in response to tokenism. Pers. Soc. Psychol. Bull. 23(12) 1277-1290.

Wright, S.C., D.M. Taylor, F.M. Moghaddam. 1990. Responding to membership in a disadvantaged group: From acceptance to collective protest. J. Pers. Soc. Psychol. 58(6) 994-1003.

Yu, A., N.A. Hays, E.Y. Zhao. 2019. Development of a bipartite measure of social hierarchy: The perceived power and perceived status scales. Organizational Behavior and Human Decision Processes 152 84-104.

Zohar, D.M., D.A. Hofmann. 2012. Organizational culture and climate. S.W.J. Kozlowski, ed. The oxford handbook of organizational psychology. Oxford University Press, New York, 643-666. 
Figure 1

Theoretical Model

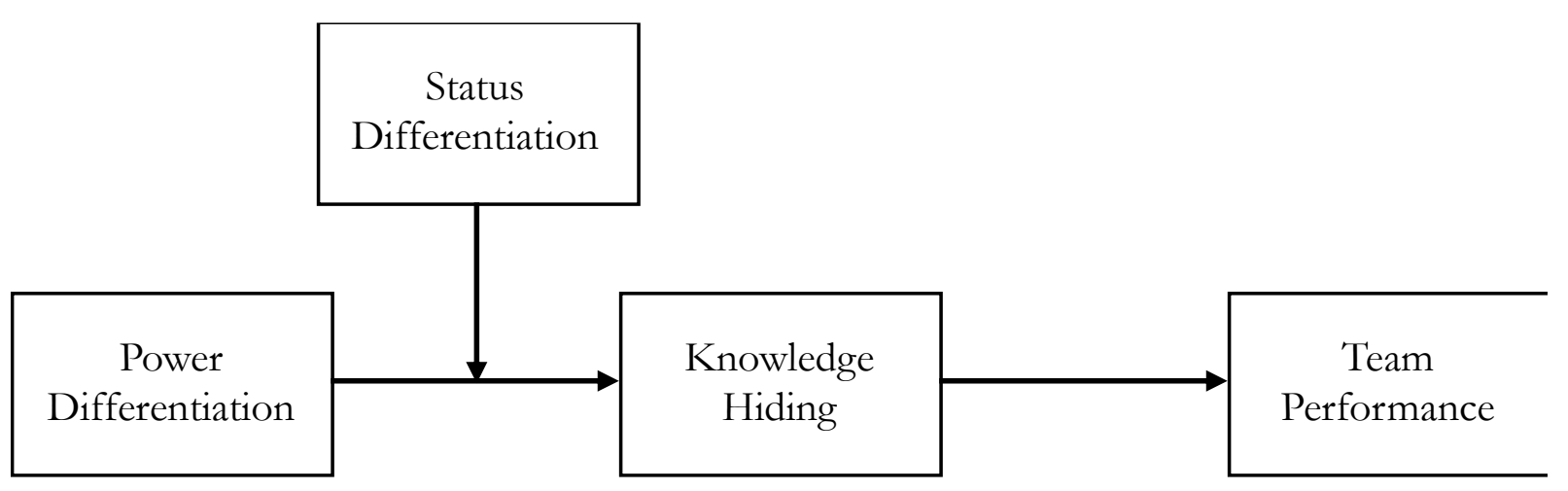


Table 1

Means, Standard Deviations, and Correlations of Study Variables

(a)

\begin{tabular}{|c|c|c|c|c|c|c|c|c|c|}
\hline Study $1(N=50$ teams $)$ & Mean & S. D. & 1 & 2 & 3 & 4 & 5 & 6 & 7 \\
\hline 1. Power differentiation & .09 & .10 & - & & & & & & \\
\hline 2. Status differentiation & .02 & .03 & $.41 * *$ & - & & & & & \\
\hline 3. Knowledge hiding & 2.32 & .51 & $.29 *$ & .01 & - & & & & \\
\hline 4. Team performance & 5.62 & .63 & -.15 & .18 & $-.40 * *$ & - & & & \\
\hline 5. Mean power & 5.32 & 1.02 & $-.57 * *$ & $-.38 * *$ & -.12 & -.06 & - & & \\
\hline 6. Mean status & 6.49 & .36 & -.24 & -.47 & .12 & -.19 & .22 & - & \\
\hline 7. Gender composition ( $\%$ of females) & .30 & .28 & -.16 & -.18 & .11 & -.12 & .20 & .04 & - \\
\hline 8. S. D. of knowledge hiding & .70 & .29 & .06 & -.02 & $.38 * *$ & $-.33^{*}$ & -.03 & .11 & .14 \\
\hline
\end{tabular}

(b)

\begin{tabular}{|c|c|c|c|c|c|c|c|c|}
\hline Study $2(N=63$ teams $)$ & Mean & S. D. & 1 & 2 & 3 & 4 & 5 & 6 \\
\hline 1. Power differentiation ( $=1$ vs. equality $=0$ ) & .49 & .50 & - & & & & & \\
\hline 2. Status differentiation ( $=1$ vs. equality $=0$ ) & .49 & .50 & -.02 & - & & & & \\
\hline 3. Knowledge hiding & 2.37 & .40 & .08 & $.32 *$ & — & & & \\
\hline 4. Team performance & 32.13 & 47.17 & .16 & -.07 & -.25 & - & & \\
\hline 5. \% of native English speakers & .70 & .21 & .05 & -.18 & $-.49 * *$ & .13 & - & \\
\hline 6. Gender composition ( $\%$ of females) & .45 & .21 & -.16 & -.19 & -.24 & -.21 & -.01 & - \\
\hline 7. S. D. of knowledge hiding & 1.02 & .34 & .02 & .03 & $.33 * *$ & .05 & -.20 & .05 \\
\hline
\end{tabular}

(c)

\begin{tabular}{|c|c|c|c|c|c|c|c|c|}
\hline Study $3(N=178$ participants) & Mean & S. D. & 1 & 2 & 3 & 4 & 5 & 6 \\
\hline 1. Equality condition $(=1)$ & .25 & .43 & - & & & & & \\
\hline 2. Alignment condition $(=1)$ & .25 & 43 & $-.33 * *$ & - & & & & \\
\hline 3. Orthogonal condition $(=1)$ & .25 & .43 & $-.33 * *$ & $-.33 * *$ & - & & & \\
\hline 4. Misaligned condition $(=1)$ & .25 & .43 & $-.33 * *$ & $-.33 * *$ & $-.33 * *$ & - & & \\
\hline 5. Knowledge hiding & 2.28 & 1.36 & $-.17 * *$ & .01 & .07 & $.10^{*}$ & - & \\
\hline 6. Competitive team climate & 3.70 & 1.63 & $-.28 * *$ & $-.09 *$ & $.13 * *$ & $.23 * *$ & $.40 * *$ & - \\
\hline 7. Cooperative team climate & 4.96 & 1.43 & $.27 * *$ & $.12 * *$ & $-.15^{* *}$ & $-.24 * *$ & $-.32 * *$ & $-.67 * *$ \\
\hline
\end{tabular}

Note. $* p<.05$. $* * p<.01$. 
Figure 2

Interactive Effect of Power Differentiation and Status Differentiation on Knowledge Hiding (Study 1)

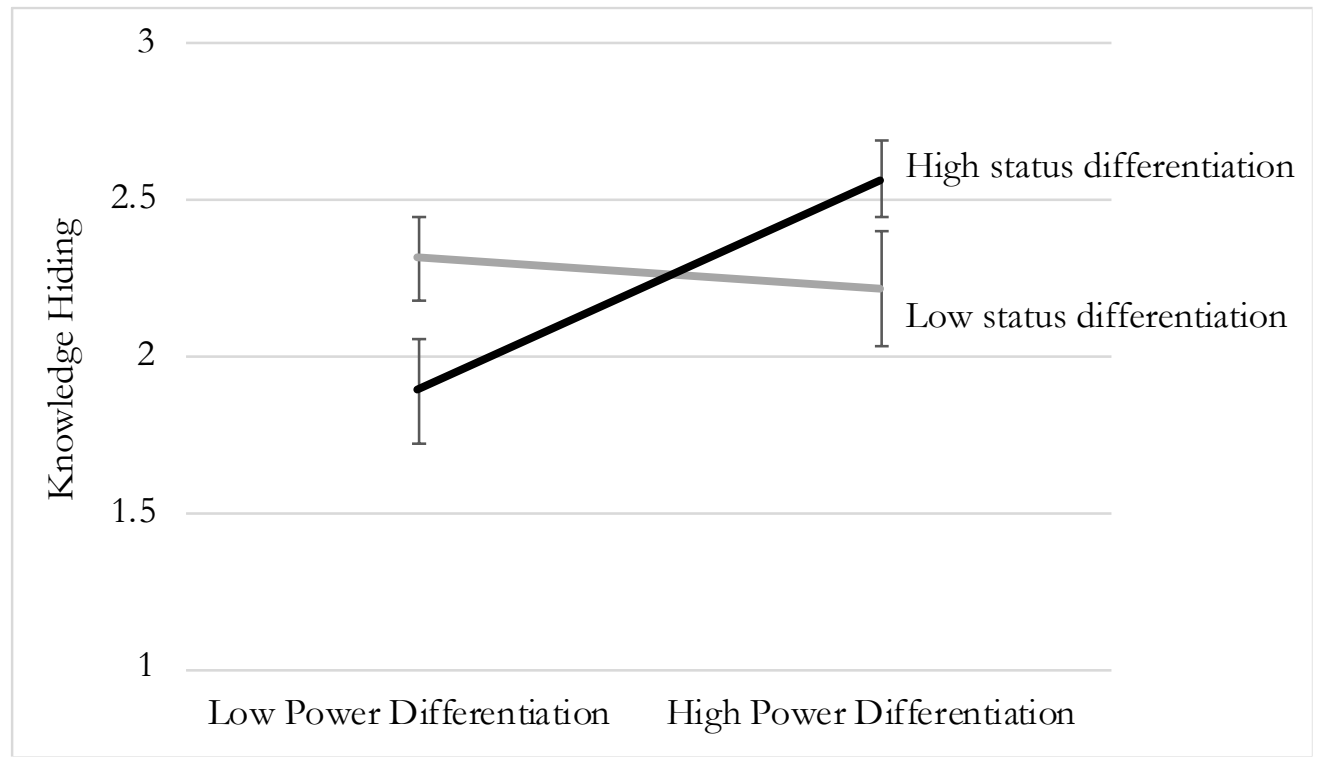

Note: Error bars represent standard error. 
Figure 3

Interactive Effect of Power Differentiation and Status Differentiation on Knowledge Hiding (Study 2)

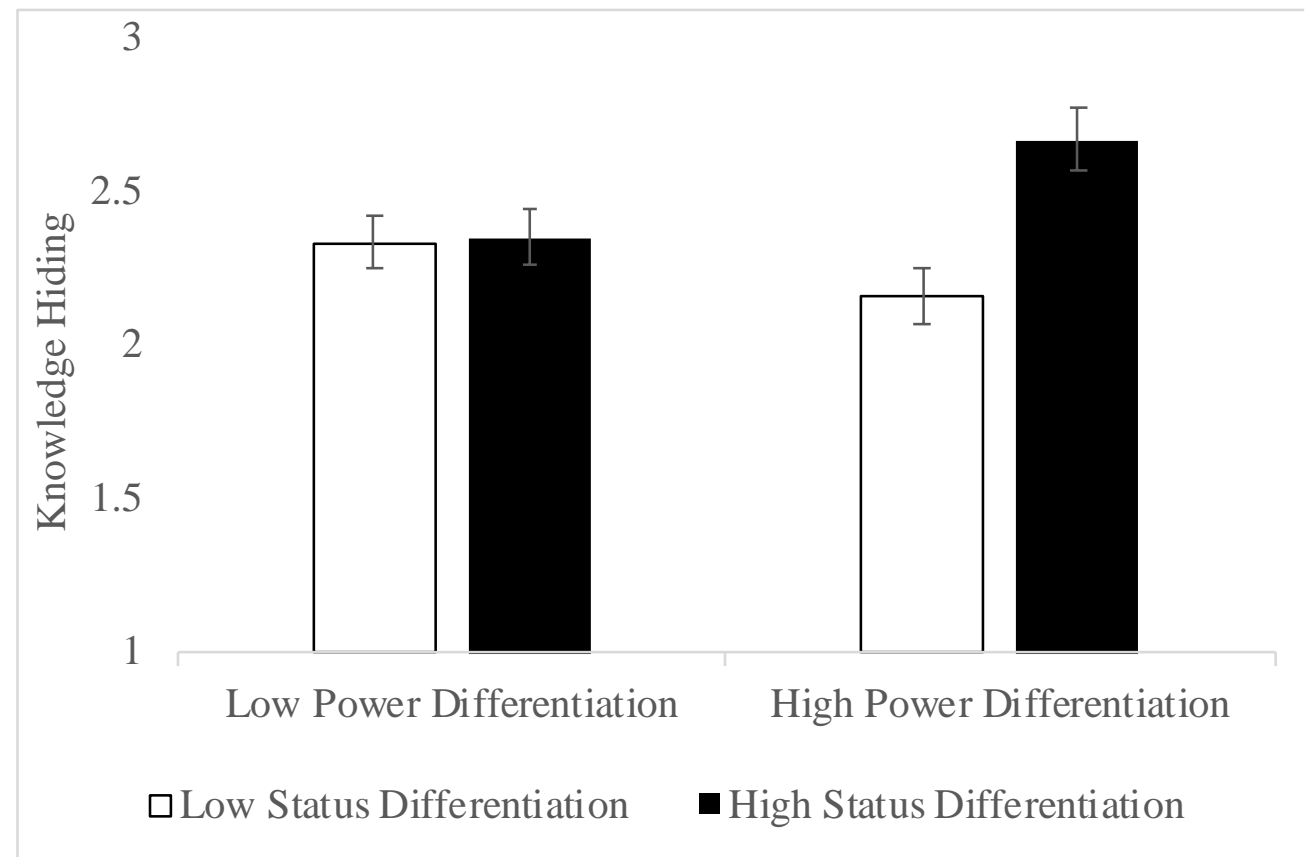

Note: Error bars represent standard error. 
Figure 4

Means of Knowledge Hiding, Competitive and Cooperative Climate by Condition (Study 3)

(a)

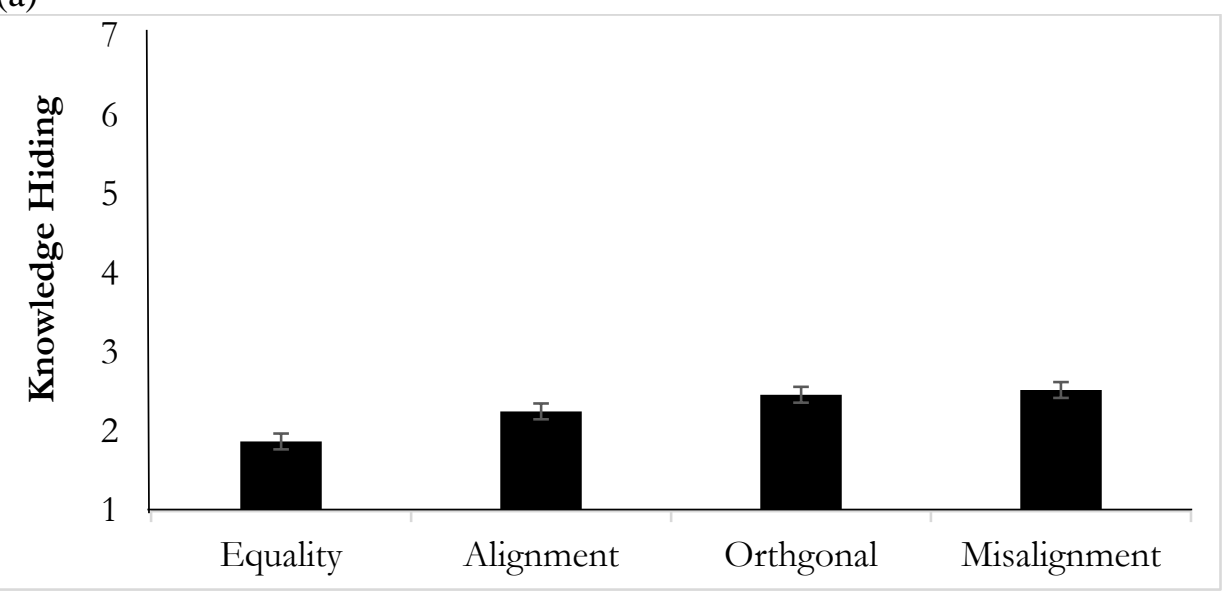

(b)

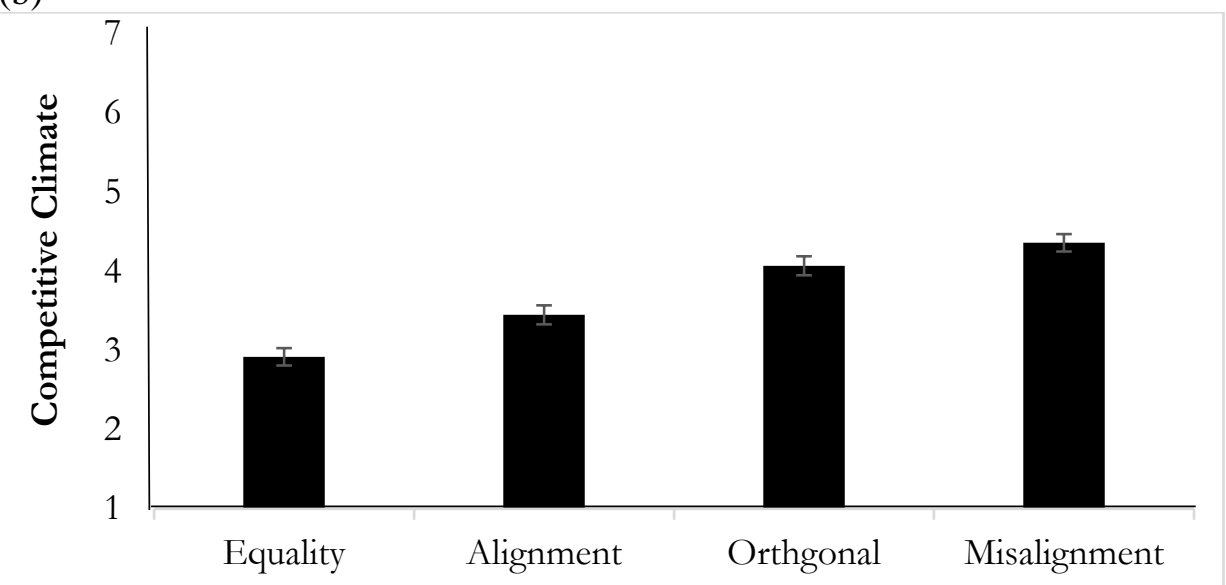

(c)

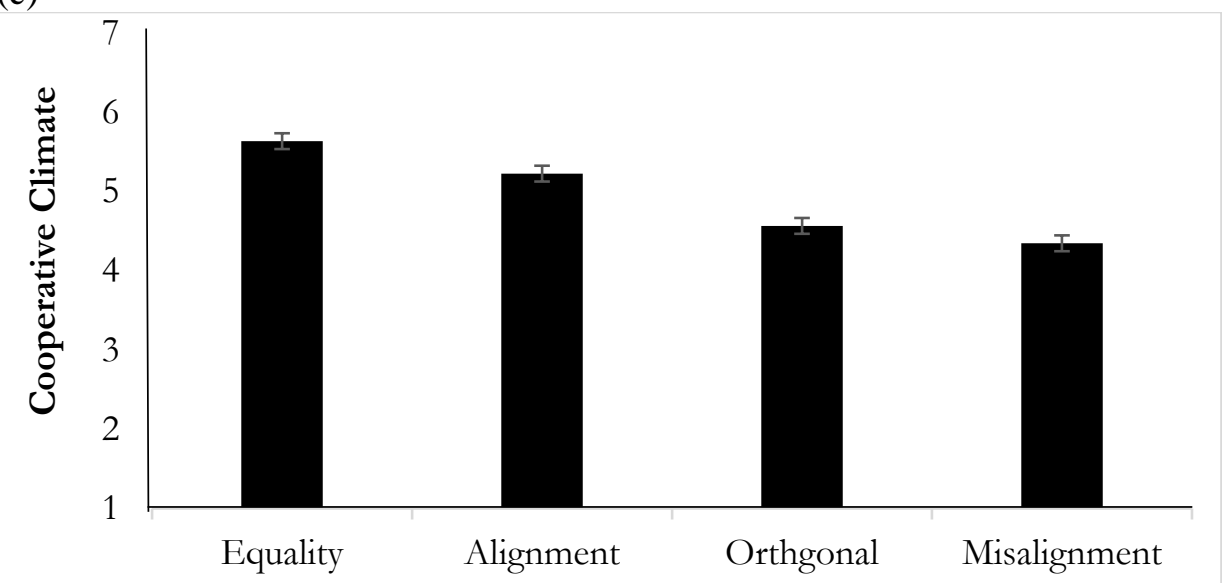

Note: Error bars represent standard error. 


\section{University Library}

\section{- M M N E R VA A gateway to Melbourne's research publications}

Minerva Access is the Institutional Repository of The University of Melbourne

\section{Author/s:}

Hays, NA;Li, HJ;Yang, X;Oh, JK;Yu, A;Chen, Y-R;Hollenbeck, JR;Jamieson, BB

Title:

A Tale of Two Hierarchies: Interactive Effects of Power Differentiation and Status Differentiation on Team Performance

\section{Date:}

2021-12-08

\section{Citation:}

Hays, N. A., Li, H. J., Yang, X., Oh, J. K., Yu, A., Chen, Y. -R., Hollenbeck, J. R. \& Jamieson, B. B. (2021). A Tale of Two Hierarchies: Interactive Effects of Power Differentiation and Status Differentiation on Team Performance. ORGANIZATION SCIENCE, 33 (6), https:// doi.org/10.1287/orsc.2021.1540.

Persistent Link:

http://hdl.handle.net/11343/294994 